\title{
Priestley's views on the composition of water and related airs
}

\author{
Geoffrey Blumenthal ${ }^{1}$
}

Published online: 4 May 2018

(C) The Author(s) 2018

\begin{abstract}
In some views in the history, philosophy and social studies of chemistry, Joseph Priestley is at least as well-known and cited for his objections to the new chemistry and his promotion of his own late version of the theory of phlogiston, as for his early series of discoveries about types of air for which he had become famous. These citations are generally not associated with any detailed indications about his late work from 1788 onwards and his late phlogistic theory, of which there has not been a detailed study. This paper undertakes a detailed study of Priestley's late work on water and related airs. He put forward a theory to support which his apparatus and initial substances would have needed to exclude impurities altogether. His theory did not take into account the solutions to the difficulties with the experiment which had been comprehensively understood and published by the phlogistian Cavendish several years previously, and with which the Lavoisians were in agreement. Priestley readily and fundamentally changed his interpretations of experiments in order to support the theory he currently favoured, and he was highly selective about replying about the criticisms of any opponent. This detailed analysis shows many divergences between his own practices and aspects of his objections to the new chemistry, which have implications for those stances in the secondary literature which do not question his objections. Accordingly, this study has implications concerning the nature of chemistry and other sciences, how they do progress and how they should progress.
\end{abstract}

Keywords Phlogiston - Chemical revolution · Priestley $\cdot$ Water and related airs

Geoffrey Blumenthal gb0859@bristol.ac.uk

1 University of Bristol, Banbury, UK 


\section{Introduction}

There has been no detailed study of Priestley's late work in chemistry from 1788 onwards, including his late phlogistic theory. This paper undertakes a detailed study of Priestley's late work on water and related airs. ${ }^{1}$ This detailed analysis shows many divergences between his own practices and aspects of his objections to the new chemistry. The following are the most noteworthy of his objections:

He (1800, p. xi) said to the antiphlogistians that "no man ought to surrender his judgement to any mere authority", and that as "you would not, I am persuaded, have your reign to resemble that of Robespierre, few as we are who remain disaffected, we hope you would rather gain us by persuasion, than silence us by power" (1800, p. xi). He suggested to the antiphlogistians that "If you gain as much by your answer to me, as you did by that to Mr. Kirwan, your power will be universally established, and there will be no Vendée in your dominions". He argued that he had not seen "sufficient reason to change my opinion" (1800, p. 2) and that "I cannot help thinking that what I have observed in several of my former publications has not been sufficiently attended to, or well understood" (1800, p. 3). He claimed that "no person who has made near so many experiments as I have, has made so few mistakes" (1800, p. 4). He claimed his apparatus "was perfectly simple, so that nothing can be imagined to be less liable to be a source of error" (1800, p. 48) while the apparatus of the antiphlogistians "does not appear to me to admit of so much accuracy as the conclusion requires, and there is too much of correction, allowance and computation in deducing this result" (1800, p. 44).

The later commentators who have taken these objections literally, have included those who have not distinguished between the differing qualities of Priestley's early and late work in chemistry. His (e.g. 1775, pp. xxxv-xlii) early apparatus for releasing air from solids had indeed been simple, cheap and effective for some of the purposes for which Priestley used it. This apparatus had made possible his early series of discoveries about types of air, especially "dephlogisticated air", 2 due to which he had rightly become and remained famous, and which led to the involvement of many other participants in the field of the chemistry associated with types of air.

However, there were several fundamental differences between this early work and his work from 1788 onwards, in which the central experiment involved burning dephlogisticated air and light inflammable air $^{3}$ to form a liquid. A large amount of gas was needed to produce a small amount of liquid, and as a result the apparatus that was needed to test the main issues was fundamentally larger and more expensive than his apparatus for releasing air from solids, as was demonstrated even in the case of the apparatus used by Cavendish $(1784,1785)$. Yet much more importantly, Priestley (1788a) came up with a theory that effectively required his apparatus and initial substances to be free from impurities and that did not take into account Cavendish's already-published outstanding series of experiments.

\footnotetext{
1 This paper is a detailed study of matters some of which were covered very briefly by Blumenthal and Ladyman (2017a).

2 This was Priestley's name for the air which Lavoisier called "pure air", "vital air", and later "oxygen" gas.

3 This was the gas on which Cavendish (1766) had done extensive research and which Lavoisier later called "hydrogen" gas.
} 
Cavendish had found that, despite the presence of phlogisticated air [nitrogen] in the initial airs or apparatus, pure water was produced if there was an excess of inflammable air over that required to combine with the dephlogisticated air (1784, pp. 136-137), or if the experiment was conducted at relatively low temperature $(1784$, p. 134). If there was an excess of dephlogisticated air, then a little nitrous acid was produced. When the dephlogisticated air was very pure, introducing a little additional phlogisticated air made the resulting liquid more acid (1784, pp. 138-139), but when atmospheric air was used so that there was a very high proportion of phlogisticated air, less acid was formed (1784, pp. 133-134). Cavendish also found (1785) that nitrous acid was only formed when both dephlogisticated air and phlogisticated air were present, and was not formed when only phlogisticated air was present in an experiment (Blumenthal and Ladyman 2017a). By the end of May 1785, the Lavoisians knew and agreed with these experimental results. In contrast, Cavendish's theory that nitrous acid in the result was the result of decomposition of the phlogisticated air, was disputed by the Lavoisians via Berthollet's letter to Blagden of 17 June $1785 .{ }^{4}$ Cavendish unofficially gave up phlogiston by January $1787 .{ }^{5}$ His acceptance of the Lavoisians' view on the composition of nitrous acid was indicated by the title of his (1788) paper. So by the start of 1788, the relevant experiments were understood in great detail by both Cavendish and the Lavoisians, and the problems of Cavendish's interpretations had already been identified and accepted.

The first of Priestley's (1788a) late papers started from the theories that nitrous acid was always formed in the results of the combustion together of pure air and inflammable air, and that it resulted from the main gases in the experiment and not from impurities. These theories could only have been established by conducting experiments in which there were effectively no initial impurities. In effect, Priestley took on an experimental task that his targeted opponents understood in great detail and knew was impracticable, in support of theories which his opponents knew could not be accurate. Yet he promoted his own point of view with arguments of which the most noteworthy have been covered at the start of this introduction. As noted, this has become of much wider importance in that Priestley's work and arguments have become central to a number of subsequent stances concerning the nature of chemistry in particular, and science in general.

The purposes of this paper are to explore Priestley's late work on water and related airs in detail, to explore the issues of this work in relation to his arguments against the Lavoisians, and to explore some wider implications. The next section examines separate topics in Priestley's work on water and related airs in detail and in context. The following section discusses Priestley's general complaints against the Lavoisians in the light of his own theory and rhetorical strategies. The penultimate section gives a brief survey of selected secondary literature. The last section gives some conclusions.

\footnotetext{
${ }^{4}$ This letter is Royal Society reference number CB1/1/217, folio number b.126a, and was published by Sadouin-Goupil (1971).

${ }^{5}$ As stated in the postscript of the letter from Kirwan to Guyton on 2 April 1787, Grison et al. $(1994,167)$.
} 


\section{The hypotheses within Priestley's late theory of water, their development, and Priestley's reactions to criticisms}

This section is divided into seven sub-sections, each of which deals with one aspect, or a small number of aspects, of Priestley's relevant experiments or interpretations. These are examined diachronically and in detail, including the context of the published chemistry that was available to him and the criticisms of his work that were made to him.

\section{The hypothesis that inflammable air consists of water plus phlogiston}

After the criticisms of Priestley's work by Lavoisier (1783a) and Cavendish (1784), it was on inflammable air that Priestley came to the first of his new subsequent views. His (1785a) publication after the 1784 debates was unusual within his output, both in that it included a statement of mea culpa, ${ }^{6}$ and in the degree to which he (1785a, p. 279) explicitly deferred to the work of others including Cavendish, Watt and Lavoisier.

Although he (1785a, p. 291) repeated Lavoisier's experiment on sending steam "through a red-hot iron tube", and argued that "for a long time" he thought that Lavoisier's view "that the inflammable air came from the decomposition of" the water was accurate, he argued that he eventually followed Watt's opinion and became "satisfied" that the inflammable air came principally from the iron. Priestley also took into account Cavendish's (1784, p. 137) questioning of Priestley's experiment "of expelling inflammable air from iron by heat alone" and Cavendish's view that "I think it much more likely, that the inflammable air was formed by the union of the phlogiston of the iron filings with the water dispersed among them". Priestley (1785a, p. 289) now repeated the experiment with "iron filings in a gun barrel", deliberately using no precaution to dry the apparatus or materials, in which case they gave inflammable air for many hours but then stopped, but re-started if water was added. He now proposed that there had been an "influence of unperceived moisture" in his previous experiments. He noted that Cavendish had made what was in effect an inferential leap to the view that water even entered into inflammable air "as a constituent principle" (Priestley 1785a, p. 288).

Priestley now undertook some more experiments on this topic. In one of these, he (1786, pp. 138-142) 'decomposed' together dephlogisticated air and inflammable air, and this involved inflammable air (from iron and oil of vitriol) being issued directly and progressively and burned in a glass balloon through which a current of air was passing, and the produce was water that was "perfectly free from acid". Priestley reported that the weight of the water was "never quite so much as the weight of the air decomposed" (1786, p. 139). Yet it is not clear how he could have weighed either gas involved because the inflammable air was issued progressively and the dephlogisticated air came from air passing through. Priestley now performed a variant of the experiment in which instead of lighting the inflammable air he put balls of hot iron into the balloon, but no water was produced. On the basis of these two experiments he (1786, p. 140) concluded that "that the water comes from the decomposition of the air and not from the fresh air circulating". It is not clear how he thought that this followed from the result of the experiments. If he meant

\footnotetext{
${ }^{6}$ Another had been included in his (1775) and was about his (1774) speculation that acid air and phlogiston were the basis of atmospheric air.
} 
that he was decomposing the inflammable air, and if he had weighed the incoming inflammable air and the resulting water, then he would presumably have found that his resulting water was greatly in excess of the weight of the inflammable air.

Priestley (1786, p. 141) then followed Cavendish's interpretative leap, from his interpretation of the results of these two experiments to the conclusion that this experiment showed "that water is an essential ingredient in the constitution of inflammable air, at least as procured from iron". Priestley later gave the title "experiments which prove that water is a necessary ingredient in inflammable air" to a section in his "methodized" volumes (Priestley 1790a, p. 66). In this case, after his (1790a, pp. 274-275) conclusion that water was essential to the production of inflammable air from iron, he then rephrased (1790a, p. 277) this without any further evidence as "water is an essential ingredient in the constitution of inflammable air".

\section{The hypothesis that dephlogisticated air consists of water plus the "principle of acidity"}

Priestley published his new concept of the composition of dephlogisticated air around three years after his concept concerning inflammable air. On this occasion he differed from Cavendish's concept. Cavendish's (1784) view that this gas was "dephlogisticated water" was even weaker than his view on inflammable air, in that Cavendish had no evidence that dephlogisticated air contained water, the theory contained nothing that indicated how dephlogisticated air promoted or caused acidity, and the hypothesis that phlogiston was taken away from water weakened the implicit Stahlian case that water was the basis of fluidity.

The first unprecedented part of Priestley's late theory was his hypothesis that dephlogisticated air consisted of water and the "principle of acidity". ${ }^{7} \mathrm{He}$ advanced this even though he (1786, p. 54) had stated that there was no acid in dephlogisticated air. Priestley (1788a, p. 147) argued that he was taking the concept of the "principle of acidity" from Lavoisier, for whom dephlogisticated air was, or contained this principle. However, Lavoisier's "principle of acidity" was oxygen which formed an air when heated, rather than necessarily a constituent of oxygen, which had very different compositional consequences from Priestley's new view of dephlogisticated air. Not the least of the differences was that in practical effect, Lavoisier's (1778) "principle of acidity" was an experimentally-accessible substance, ${ }^{8}$ whereas Priestley's was an experimentally-inaccessible constituent. ${ }^{9}$ So in this case, the only part of Cavendish's view that Priestley followed was that dephlogisticated air contained water. It was this part of his new view that was to some extent experimentally

\footnotetext{
7 (1788a, p. $154 ; 1788$ b, p. $314 ; 1790$ c, p. 535). It is not clear in his (1788a) paper that he thought of these as the only constituents of water, but in his (1788b) paper he states "I am inclined to think, that not much more than one-twentieth part of the dephlogisticated air is the acidifying principle, and that nineteen parts are water".

8 This was clearly the case in the option in which caloric, the "cause of heat" was the motion of molecules. Also, in the option in which caloric was a material substance, it was imponderable or practically so, in which case oxygen could be experimentally tested by weight while caloric could be experimentally tested by temperature.

9 Nearly all Priestley's references are to a "principle of acidity" which was a constituent, the exception being (1794, p. 8) in which he "temporarily accepted Lavoisier's designation of dephlogisticated air as the acidifying principle" (Schofield 2004, p. 307).
} 
assessable, and therefore it was this part of the view that was criticised at the time, and this is the topic of the rest of this section.

Priestley (1788a, pp. 152-154) attempted to support his equivalent hypothesis just by analogy. He argued "that a considerable quantity of water enters into the composition of dephlogisticated air, will not be thought improbable, when it is considered that, in my former experiments, this appeared to be the case with inflammable air. For without water this air cannot be produced". Priestley (1788a, p. 152) reported one set of experiments which he argued gave support by analogy to the view, and which involved the substance that Withering (1784) had identified and called terra ponderosa aerata (t.p.a.) ${ }^{10}$ Priestley reported that this substance gave no fixed air by mere heat, ${ }^{11}$ but when steam was sent over it, in a red heat, fixed air was produced, and in the same quantity as when t.p.a. was dissolved in spirit of salt. ${ }^{12}$ Priestley reported that "making the experiment with the greatest care, I find that fixed air consists of about half its weight of water". Priestley (1788a, p. 152) argued that this supported his view that every air contained water.

Rupp (1798, p. 152) rightly argued that Priestley's whole late theory depended on this "opinion". Maclean (1797, p. 50) and Rupp (1798, p. 153) identified that the first of Priestley's statements about t.p.a. was now known to be incorrect, in that Dr. Hope of Edinburgh had "discovered that the carbonic acid can be separated from the barytes, by exposing the compound to such a temperature as can be raised in a smith's forge". ${ }^{13}$ Maclean argued that the disengagement of the carbonic acid took place at a lower temperature when water was used. Berthollet (1789) proposed that the impression that fixed air contained water was because, at the heat in the experiment, the emitted carbonic acid contained a quantity of dissolved water which it would deposit on returning to atmospheric temperature. Maclean (1797, pp. 49-50) echoed this and stated that "every chemist knows that it has that property, and in a greater degree at a high than at a low temperature”. Berthollet (1789, p. 82), followed by Maclean and by Rupp (1798, p. 153), argued that Priestley's calculation could not be relied on since he had not examined the loss of weight of the t.p.a. Maclean (1797, p. 51) concluded that these experiments "afford no support to the Doctor's principles". Rupp (1798, pp. 154-157) performed five different experiments to examine whether fixed air contained water, in each case documenting the actual experiment and calculating what the result would have been, if fixed air contained water, and concluded that it did not.

Concerning weighing the t.p.a. after the experiment, Priestley (1800, p. 58) argued that after the process the resulting solid "adhered so closely to the earthen tube in which the experiment was made, that the loss of weight could not be ascertained with accuracy". However, it would have been practicable to weigh the t.p.a. and the container before and after the experiment, which would have shown the weight loss of the t.p.a., and the weight gain of the container. ${ }^{14}$ Priestley did not deal with the objection that fixed air could be

\footnotetext{
${ }^{10}$ Now Witherite, barium carbonate, $\mathrm{BaCO}_{3}$. Withering (1784) showed that this was not the same as barytes, which was Kirwan's name for the substance discovered by Scheele in 1774 which is now known as $\mathrm{BaSO}_{4}$.

11 This was Withering's (1784) conclusion.

12 Spirit of salt is now hydrochloric acid, $\mathrm{HCl}$. In modern terms, the reaction gives acqueous Barium Chloride plus $\mathrm{CO}_{2}$ and water.

13 Although the reference here is to "barytes", actually Hope had found that Witherite decomposed into what is now called Barium oxide and $\mathrm{CO}_{2}$ at temperatures above $1000{ }^{\circ} \mathrm{C}$. (c.f. Murray 1819, v. 3, p. 21).

14 Apart from experimental errors, the difference between these weights would have indicated the weight of the fixed air that had actually been produced, which would have supported the conclusion that the water content in the fixed air was not integral.
} 
produced from t.p.a. without the use of water, which was the central objection to his view. Priestley (1800, p. 58) argued that finding the loss of weight of his solid was "not at all necessary.... It was quite sufficient... to find how much water was expended in producing any quantity of fixed air from this substance... as there was no other source of loss of water besides the fixed air, it could not but be concluded that it had entered into its composition, as a necessary part of it". However, this was inaccurate - the alternative, as Berthollet and Maclean had already noted, was that water was dissolved in the carbonic acid at its current high temperature, and the experimental result that fixed air could be produced from t.p.a. without the presence of water supported this view.

Priestley (1800, p. 58) did note that Rupp had produced several experiments "made seemingly with great accuracy, to prove that fixed air contains no water", ${ }^{15}$ to which Priestley did not reply other than by arguing that they were much more complex than his own and therefore that they did not "authorize so positive a conclusion". It is noteworthy that this type of allegation could be made about any experiment whose conclusions did not favour Priestley's theory. This was just one of the arsenal of purely rhetorical responses that he was using by that date.

In addition, the view that water was present as an (unisolatable) integral constituent in some or all gases could not be definitely invalidated at that time by such experiments and inferences, and not only it had been put forward by Stahl, but also it had recently been supported in the cases of inflammable air and dephlogisticated air by Cavendish. From now on, Priestley (c.f. 1800, p. 58) held the view that probably "water is the basis of all kinds of air". He also argued that water might even be the whole of the weight of some gases (1800, p. 46).

For these unfounded views on the composition of inflammable air and dephlogisticated air, Priestley could rely either on the authority of Cavendish or on his partial precedent. For the remainder of his late experiments and theories on water and related airs, he was on his own, and in all crucial respects he differed from both Cavendish and Lavoisier without properly taking into account not only their and his own prior work but also the criticisms he received.

\section{The degree of purity of the airs entering the experiment}

As already identified, Cavendish and Lavoisier each considered that fully excluding impurities from the initial substances and the apparatus was not practicable, and they recognised that the small amount of nitrous acid that was found under some conditions in the result was due to impurities, while Cavendish had showed how to eliminate nitrous acid from the result despite remaining impurities of phlogisticated air in the initial airs or the apparatus. By contrast, Priestley's (1788a) theory presented him with a totally different order of experimental problem, because in order to substantiate his view that small quantities of substances other than water that were present in the results had been integral to the reaction and not due to impurities, his apparatus and substances needed effectively to exclude

\footnotetext{
${ }^{15}$ Murray $(1819$, p. 327) later confirmed that "carbonic acid contains no combined water... it is a binary compound of carbon and oxygen... No water is deposited from it when it enters into saline combinations; it can be formed from dry and perfectly calcined charcoal, or, what is less ambiguous, from diamond and dry oxygen".
} 
substances other than dephlogisticated air and inflammable air from the initial conditions of the experiment.

Priestley started by arguing that his dephlogisticated air was "exceedingly pure" (1788a, pp. 151-152) without any supporting information concerning how he had dealt with or avoided the occurrence of impurities. He stated that his dephlogisticated air for these experiments was produced successively from manganese, minium, red precipitate, mercurius calcinatus, or finally the "yellow product". ${ }^{16}$ Yet he $(1775$, p. 49) had stated that it was necessary to extract fixed air from calces before making his experiments, he (1779, p. 394) recognised the issue of fixed air in calces, while on one occasion he (1786, p. 5) stated that he had extracted fixed air from his calces. He (1788a) did not state any such precaution, and in any case, there was no equivalent known method for removing phlogisticated air from other airs, although the degree of purity of dephlogisticated air from calces could be improved by discarding the first produce of air from any calx.

This and his next (1788b) paper resulted in protests that Priestley had ignored Cavendish's work which concluded that the nitrous acid and the fixed air in the results of this type of experiment were due to impurities. ${ }^{17}$ Priestley now made one of the temporary complete U-turns which, as will be seen in several sub-sections below, characterise his work on this topic. He (1789, p. 11) admitted that phlogisticated air "could not be excluded, whether it was by that which remained in the vessel after exhausting it by the air pump, or that with which the dephlogisticated air was more or less contaminated".

Entirely reasonably, the topic of impurities became a focus of the Lavoisians' published criticisms of Priestley's (1788a, b, 1789) papers, starting with those of Berthollet (1789). The latter (1789, p. 67) noted that Cavendish had clarified that all metallic oxides prepared in air contain carbonic acid. Berthollet $(1789$, p. 89) also noted that Priestley had not taken into account Cavendish's careful work on the effects of varying amounts of azote gas in the water experiment and their results. Berthollet (1789, pp. 68-73) noted that Monge had not used the first parts of the air that had been disengaged from his calx, and that the result had been much purer vital air.

Berthollet (1789, p. 73) now noted that in an experiment using lead oxide, Priestley (1786, p. 5) had initially heated the oxide thereby removing a quantity of air which was not all the air, as Priestley argued, but some of it including the carbonic acid that had been absorbed into the oxide. Berthollet (1789, p. 74) stated that "by means of these precautions, which he entirely neglected afterwards, Priestley reduced metallic oxides by hydrogen gas without obtaining carbonic acid". By contrast, having left lead oxide, which had been prepared like the former sample, exposed to the air during several weeks, Priestley found a considerable quantity of azote gas in the residue of his experiment, and when putting the same oxide in the fire, it also gave a considerable quantity of azote gas. Accordingly, Berthollet accurately judged that the azote gas in Priestley's residue had been absorbed from the atmosphere into his calx.

Berthollet (1789, pp. 90-94) discussed Priestley's (1789, pp. 11-12) experiment taking the dephlogisticated air from some mercuric oxide that Berthollet had sent him. Priestley had reported that this never gave carbonic acid via heating. Berthollet (1789, pp. 91-92) had retained half of the sample from which he had sent the other half to Priestley, and now heated it, receiving the resulting air over lime water. There was no change to the lime

\footnotetext{
16 This was the yellow version of mercuric oxide that is produced from a solution of mercury in spirit of nitre (nitric acid).

17 (Priestley 1789, p. 7) C.f. Priestley's letters to Wedgewood, (Bolton 1891, pp. 91 and 95).
} 
water for half an hour, but then a deposit started forming. Berthollet explained that some carbonic acid was suspended in the vital air, that air had more affinity for carbonic acid than did lime water, and when air contained as much carbonic acid as it could in saturation, it was not easy to separate this with lime water, as Cavendish had previously pointed out. Berthollet (1789, p. 92) added that when vital air was disappearing rapidly, as when water was being formed, then the carbonic acid that was freed from the vital air was easily apparent. Berthollet (1789, pp. 93-94) also noted that the quantities of carbonic acid in Priestley's experiment did not exceed those that would have been contributed by the mercuric oxide. After having extracted the carbonic acid from the air from this sample of mercuric oxide, Berthollet (1789, pp. 94-95) then inserted a sulphur compound to take out the vital air, leaving a third of the air remaining as a residue, which was azote gas. On this basis Priestley's "very pure" dephlogisticated air had actually contained not only carbonic acid but also one-third of its volume of azote gas.

Concerning Berthollet's criticisms concerning impurities of phlogisticated air in his incoming dephlogisticated air, Priestley had told Wedgewood in October 1790, (Bolton 1891 , p. 103) that "the air I use is not as pure as theirs", which contrasted with his previous argument that it was "exceedingly pure" (1788a, pp. 151-152). He now changed to obtaining his dephlogisticated air from the yellow oxide of mercury procured from nitrous acid, and therefore away from all the specific oxides which Berthollet had stated as including azote gas, but without giving any evidence that he was taking any more experimental precautions concerning impurities. Then on 16 February 1791 Priestley performed the opposite U-turn. He claimed to Wedgewood that "I now, with great certainty, make air so pure, that I am confident that it contains no mixed phlogisticated air whatsoever" (Bolton 1891, p. 105). On the basis of the change to the oxide he was using and one to his apparatus, he (1791, pp. 215-216) now claimed that there was nothing other than dephlogisticated air and inflammable air in his vessel. There was no way available at the time by which he could have achieved this. The 1791 paper marks the point in his work in chemistry when he began frequently to combat objections with purely rhetorical replies, as will be seen in several more instances below.

Berthollet's arguments were echoed by Maclean, who (1797, p. 47) noted that manganese oxide "ordinarily" contained a considerable quantity of azote gas and carbonic acid, that red lead absorbed azote gas from the atmosphere (1797, p. 47), and the fixed air in Priestley's results was due to initial impurities (Maclean 1797, 28). In Priestley's (1797) reply he continued his rhetoric from 1791 without giving any evidence to support his claim that his own dephlogisticated air "was purer than any that I believe they have ever pretended to have made" (1797, p. 31), and arguing that he knew well how to test the purity of his airs "when that was required" (1797, p. 33).

Concerning Priestley's incoming inflammable air, he mostly produced his inflammable air by passing steam over iron. ${ }^{18}$ By contrast, Cavendish routinely produced his inflammable air from zinc with the agency of an acid, which gave relatively pure light inflammable air. Before Priestley's (1789) paper, he had already received objections that the fixed air in the experiments might have come from the plumbago in the iron (c.f. Maclean 1797, p. 28). Priestley (1789, p. 12) argued that "since we ascertain the quantity of plumbago contained in the iron by what remains after its solution in acids, it is in the highest degree improbable, that... plumbago... should enter into the inflammable air procured from it".

\footnotetext{
18 This will have produced some airs other than light inflammable air - at least heavy inflammable air (CO) and probably fixed air $\left(\mathrm{CO}_{2}\right)$.
} 
Priestley (1789, p. 13) made the further counter-arguments that he had had the same result when his inflammable air was obtained from tin, and that the fixed air far exceeded the weight of the plumbago, which he calculated using what he stated was Bergman's information on the amount of plumbago contained in iron. ${ }^{19}$

Another issue was implicit in Priestley's (1788a, p. 149) statement that after the experiments his apparatus had the smell "of the most offensive kind of inflammable air from iron". ${ }^{20}$ The source of this may be indicated by his (1786, pp. 159-160) description of finding that kind of air, when "I happened to take some iron, parts of which had been heated by a burning lens in vitriolic acid air", ${ }^{21}$ if he was using some of that iron also in his new experiments.

\section{Problems with the apparatus}

Priestley initially tried to collect his airs in the same chamber as he made the explosion. In that case, the result was disrupted by the effect of the explosion on the liquid over which the airs were stored, which initially was mercury and which became spattered over the chamber during the explosion, so that subsequently he used two separate chambers. In order to form or to store $^{22}$ the airs without disrupting the rest of the experiment, additional vessels were presumably needed, although Priestley did not state this.

For each container used in the experiment, there was the issue of how to exclude atmospheric air before the experiment. In some of his experiments, Priestley exhausted his chambers as far as possible with an air-pump, which therefore involved the problem that Cavendish had previously identified that this process could not remove all the initial air. He (1788a, pp. 151-152) argued that in the cases of his experiments in which he had not used an air-pump he had excluded phlogisticated air, and even when his apparatus did contain phlogisticated air "it is a satisfactory answer to this objection, from the presence of phlogisticated air in the tube, that this kind of air is not decomposed, or at all affected, by this process, as will be found by mixing any quantity of it with the other two kinds of air". This last point showed that he had not yet taken on board Cavendish's (1784, pp. 133-134, 138-139) results showing the two ways in which the quantity of phlogisticated air in the initial airs did affect the result of the experiment, nor Cavendish's (1784, pp. 134, 136-137) identifications of the ways that pure water could be produced despite the presence of phlogisticated air in the experiment. As has been seen in the previous section, he (1789, p. 11) subsequently admitted that it "could not be excluded, whether it was by that which remained in the vessel after exhausting it by the air pump, or that with which the dephlogisticated air was more or less contaminated".

For the last of Priestley's experiments, reported in 1791, he tried to exclude phlogisticated air from his apparatus by storing his airs in a single chamber, initially filled with water, out of which the water was pushed by the incoming airs. Yet this storage method introduced a different potential source of phlogisticated air, in addition to that which he

\footnotetext{
${ }_{19}$ Berthollet confirmed in his 1789 paper that Bergman had given a wide range of figures for the content of plumbago in iron, but Priestley had quoted a single figure (which was an average).

20 That is, $\mathrm{H}_{2} \mathrm{~S}$.

21 In effect, his "iron" probably included iron oxide and iron sulphide due being heated in the vitriolic acid air, $\mathrm{SO}_{2}$.

${ }^{22}$ For transit-Priestley (1788a, p. 150) reported that his dephlogisticated air was supplied to him by Keir.
} 
actually could not exclude from his incoming air. He had already written a paper (1783) referring to the generation of air from water, including methods without heat, ${ }^{23}$ and he had known since his (1786) work that collecting airs over water did not provide a permanent barrier to the exchange of airs between his vessel and the atmosphere (1786, pp. 385-386). He also identified that water released air when the pressure was lowered. ${ }^{24}$ So when his initial airs entered the chamber and thereby pushed some of the initial water out of the chamber, this would have effected some exchange between the air he was introducing and the air contained as impurities in his water. ${ }^{25}$ Priestley did not take these factors into account when he (1791, pp. 215-216) now claimed that there was nothing other than dephlogisticated air and inflammable air in his apparatus.

Rupp (1798, pp. 129-130) rightly objected that making experiments over water was generally "a method which always leaves some doubt of the exactness of the result, not only on account of the attraction, which the substances under operation have to moisture, with which they may combine or which they may decompose, and thereby produce errors; but also on account of the air which water contains, and which may be expelled by the heat of the operation or attracted by the bodies under examination". Berthollet had also stated that Priestley had taken no account of the air in the vessel in which he made the experiment, implying that this was a root of some of Priestley's interpretational errors.

Priestley (1800, p. 50) argued that he "did not overlook this circumstance, since I measured the capacity of the vessel by the quantity of air that had disappeared, by having been completely decomposed in the process, so that there was no occasion whatever to take an account of the air that was not affected by it". This did not actually answer Berthollet's objection. This also did not deal with the problem that Priestley's theory could only be established via this single experiment if there were no impurities in his initial airs and apparatus.

Priestley's work had been criticised on the grounds that his experiments on the combination of dephlogisticated air and inflammable air used very small quantities and that he could not weigh his substances accurately. He (1800, p. 49) attempted to excuse this by arguing that "all the inside of my large vessel being, of course, wet with the liquor produced by the explosion, I could not pretend to weigh that which drained from it with much accuracy". ${ }^{26}$ Yet irrespective of the issues of quantities, he could also have avoided his problems with weighing his water, by firstly weighing his main vessel dry before the experiment and with its liquid contents afterwards, and simply calculating the weight difference.

\footnotetext{
${ }^{23}$ Priestley (1774, p. 59) had noticed prior to his 1772 paper an effect which was actually the absorption and emission of gases by water when storing inflammable air over water for long periods, but had not identified that this was what was happening.

24 (1793, p. 34). This was a little later than his series of experiments published in his 1788-1791 papers, but in the 1793 paper he argued that he had been doing this for a long time with the relevant apparatus. Later Priestley (1796, p. 25) recommended that distilled water should be used in those experiments on generating air from water, and he (1793, p. 26) stated that it was universal knowledge that distilled water had an eager attraction for air

${ }^{25}$ Later Henry (1803, p. 276) found that 100 cubic inches of water at $60{ }^{\circ} \mathrm{C}$ and standard pressure would absorb 3.55 cubic inches of oxygen gas, or 1.47 cubic inches of azotic gas or 1.53 cubic inches of hydrogen gas. Under increased pressure, a quantity of hydrogen gas up to one-third that of the water could be absorbed (Murray 1819, v.2, p. 107) and a quantity of oxygen gas up one-half that of the water could be absorbed (Murray 1819, v. 2, p. 18). Davy (1807, p. 11) noted that "hydrogen, during its solution in water, seems to expel nitrogene, while nitrogene and oxygene are capable of co-existing dissolved in that fluid".

${ }^{26}$ Priestley's (1788a, p. 149) procedure was to estimate the weight of the air in his container and to compare this with the actual weight of water collected.
} 
Priestley (1800, p. 49) attempted to justify the first of these points by arguing that "very little" depended on the quantity of water produced. However, this was simply inaccurate, in that a crucial part of his main case was his argument that he (1800, p. 46) "was never able to get the whole weight of the airs in water", which was part of his reason for why he had "produced" phlogisticated air, or nitrous acid, or fixed air, or nitrous air, during the experiment. He then performed a further change of argument by (1800, p. 46) also arguing that water was a constituent part of his initial gases "and for any thing that is certainly known is all that can be ascertained by weight". Nevertheless, in effect his apparatus and practices did not support any of his claims concerning the quantity of water produced in the experiment.

At one early stage Priestley had claimed that there was a high amount of acid in his results. Berthollet (1789, pp. 83-87) clarified that the supposedly high amount of acid in Priestley's (1788b) repeated experiment on water which had given larger quantities of liquid, was due to errors which had been understood and analysed previously by Cavendish. Once Priestley's liquid was exposed to air, even without heat it deposited a green powder which was insoluble in water but soluble in acids. Keir, who analysed the liquid for Priestley (1788b, pp. 323-330) decided that the acid which had been dissolving this powder 'must' have disappeared from the experiment, and therefore calculated how much 'must' have done so, thereby roughly doubling the amount of acid that actually remained in the liquid. However, Cavendish had previously identified that the nitrous acid which was the product of the experiment, once exposed to air, gained oxygen and became nitric acid. This process was accompanied by the deposition of part of the base with which the acid had previously been saturated, since as Bergman had identified, stronger acids are saturated by smaller amounts of bases. Accordingly, the liquid formed during Priestley's experiment actually contained acid which was about one forty-fourth of the quantity of the waterwhich was less in proportion than had been the case in Cavendish's equivalent experiment-instead of one-twentieth as Keir had calculated.

\section{The hypothesis that nitrous acid is an integral product of the combustion of dephlogisticated air and inflammable air}

As already noted, Priestley (1788a) initially developed his new theory on the basis of his thought that the dense vapour or acidic liquid, later identified as nitrous acid, that was formed when he did the experiment on the combination of dephlogisticated air and inflammable air, was an integral result of this reaction. ${ }^{27}$

This was a direct U-turn relative to his previous experimental interpretations, as will be noted in the sub-section on water below. He continued his recent policy of deferring to the authority of a fellow participant, in noting (1788a, p. 148) Keir's opinion "that some acid must be the produce of this experiment", and in stating that without Keir he might not have found the acid, even though in other cases he successfully used litmus to test for acid. Priestley (1788a, p. 149) stated that after every explosion "the vessel was filled with a dense vapour", that afterwards the vessel smelt of "the most offensive kind of inflammable

\footnotetext{
27 Priestley firstly mentioned this in correspondence with Ingenhousz, Price, Wedgwood, Withering and Keir (Schofield 2004, p. 181).
} 
air from iron" and after testing with litmus, that an acid had been formed. ${ }^{28}$ Interpreting his results, Priestley (1788a, p. 151) argued that the nitrous acid ${ }^{29}$ in the experiment was formed from the phlogiston and principle of acidity released during the decomposition of the dephlogisticated air and the inflammable air.

As already noted, this and his next (1788b) paper resulted in protests that Priestley had ignored Cavendish's work. Before producing his (1789) paper, Priestley reported to Wedgewood that "I can now procure, either pure water or a dry and condensed vapour at pleasure". ${ }^{30}$ This appears to demonstrate that he had now understood part of Cavendish's (1784, pp. 136-137) results. However, he did not make this further U-turn in public for the next three years. Despite the information in his letter to Wedgewood, in the paper Priestley $(1789$, p. 7) argued that "when the experiments were conducted with due attention" he "never failed... to produce some acid". He produced a hypothesis for why he had not found the acid previously, which was that "the acid wholly escaped... [which] may easily be accounted for, from the small proportion of the acid principle in proportion to the water, and the extreme volatility of it, owing, I presume, to its high phlogistication when formed in this manner" (Priestley 1789, p. 8). However, this did not explain why the acid was now retained, and still did not take into account Cavendish's explanations (1784, pp. 134, 136-137) for how to produce results only involving water.

Priestley (1789, pp. 7-8) argued that his experiment differed from Cavendish's in that the latter's was "a very slow one by electricity, and mine is a very rapid one by simple ignition". However, Cavendish's experiments were either performed with explosion by electricity, or were slow and involved ignition by a candle. Moreover, this argument ignored Cavendish's recipe for producing pure water by using an excess of inflammable air.

Priestley $(1789$, p. 8) also argued that there was "no contradiction whatever" between his experiment and Cavendish's experiment. Priestley $(1789$, p. 8) proposed that "phlogisticated air may contain phlogiston, and by means of electricity this principle may be evolved, and unite with the dephlogisticated air (or with the acid principle contained in it) as in the process of simple ignition the same principle is evolved from inflammable air, in order to form the same union, in consequence of which, the water, which was a necessary ingredient in the composition of both types of air, is precipitated". Priestley's basic theory was that in the experiment, the water that was in each air was released, and the phlogiston and the "principle of acidity" combined to form the acid (c.f. 1789, p. 8).

Priestley (1789, pp. 8-9) now reported that he had mixed phlogisticated air with his other airs, and found that it was not affected, as in his previous experiment; he then stated that he had tried the experiment "with atmospheric air instead of dephlogisticated air", and in this case he found that the "consequence was the production of much less acid than before, the liquor I produced being sometimes not to be distinguished from pure water". This now implicitly recognised one of Cavendish's (1784, pp. 133-134) results. ${ }^{31}$ However, Priestley did not give recognition to Cavendish's (1784, pp. 138-139) other point, that

\footnotetext{
${ }^{28}$ The likely explanation of this has been given in a previous sub-section. If the smell was as Priestley reported, then his acid presumably included some sulphuric acid, as well as the nitrous acid that was identified in Keir's analysis (in Priestley 1788b).

29 Priestley was originally uncertain as to which acid this was; Priestley to Ingenhousz, 24 November 1787 , (Schofield 1966, p. 249). This was confirmed as nitrous acid by Withering; Priestley to Wedgewood, 8 January 1788, (Schofield 1966, p. 249); also Priestley (1788b, p. 321).

30 Priestley to Wedgewood, 17 August 1788 (Schofield 1966, p. 250).

31 C.f. Priestley to Banks, 18 August 1788 (Bolton 1891, p. 94). Also Priestley to Wedgewood, 18 August 1788 (Schofield 1966, p. 250), Priestley (1789, pp. 9-10).
} 
when the dephlogisticated air was very pure, adding some phlogisticated air to the experiment made the result more acid, which was fundamentally contrary to Priestley's whole theory.

Despite his maintenance in 1789 and 1790 of the public position that he always produced an acid in the experiment, which will be detailed in the section on water below, and despite what he had reported to Wedgewood in August 1788, he (1791, p. 217) subsequently stated in public that "I am now able to procure, either nitrous acid or pure water, from the same materials". In his later polemics he (e.g. 1796, p. 51) continued to argue that "when dephlogisticated air and inflammable air, in the proportion of a little more than one measure of the former to two of the latter, both so pure as to contain no sensible quantity of phlogisticated air, and inclosed... and decomposed by taking an electric spark in it, a highly phlogisticated nitrous acid is instantly produced, and the purer the airs are, the stronger is the acid found to be". In effect, he continued not to recognise the part of Cavendish's (1784, pp. 138-139) findings that disconfirmed his theory, and he also continued not to recognise the smallness of the quantity of nitrous acid in the result.

\section{The hypotheses concerning the production of other substances during the experiment}

The first of Priestley's late papers set a precedent for the type of auxiliary hypothesis that he produced when other substances were found in the results of his experiment. He simply claimed that they had also been formed in the experiment. He (1788a, p. 154) argued that the small amount of acid that was in dephlogisticated air "may well be supposed to be employed in forming the fixed air, which is always found in this process" (1788a, p. 154).

In his (1789a, pp. 11-12) repetition of the experiment, he produced the dephlogisticated air using some mercurius calcinatus which had originally been made by Cadet and of which he now sent the residue to Berthollet. He found that a considerable portion of the air that remained in the vessel was fixed air, and he now came to the conclusion that in this case it was this acid with which his liquid was impregnated, not the nitrous acid. ${ }^{32}$ Priestley (1789, p. 13) also undertook an experiment reducing mercurius calcinatus (which had been sent to him by Berthollet) in inflammable air, until his inflammable air had been reduced to a residue which was a quarter of the original, and of which a small proportion was fixed air. This, he argued, was "abundantly more than the weight of the plumbago"- this took into account the possible presence of impurities in his inflammable air but did not allow for the likelihood that his fixed air had been previously absorbed from the atmosphere into the calx. Priestley now concluded that the fixed air in the liquid was the product of the parts of dephlogisticated air and inflammable air that were not water.

His new overall argument from all these experiments was that "when either inflammable or dephlogisticated air is extracted from any substance in contact with the other kind of air... the result will be fixed air; but that if both of them be completely formed before their union, the result will be nitrous acid" (1789, p. 12; 1790c, p. 536). Priestley (1789, pp. 16-17) re-affirmed his views, arguing that his experiments "establish[ed] the doctrine of

\footnotetext{
32 Withering's report was included in the previous paper (1788b, p. 322), in which Withering had given the overall conclusion that the acid was nitrous. Priestley and Withering changed their minds concerning this experiment before Priestley's 1789 paper.
} 
phlogiston", and that "I apprehend it will not be denied, that the produce of this decomposition is not mere water, but always some acid".

When he (1791, p. 217) finally stated publicly that the result was not always some acid, he (1791, p. 213) still did not deal with Cavendish's (1784) indications that fixed air was an impurity, nor with Berthollet's criticisms of his views on the formation of fixed air from dephlogisticated air and inflammable air, but merely argued without giving any evidence that this formation was "sufficiently evident". This was a direct echo of a rhetorical technique that Priestley had used in his ecclesio-political controversies-for example, he (1785b, p. 544) had claimed that "it is sufficiently evident that Unitarian principles are gaining ground every day" even though "for the present we see no great number of churches professedly Unitarian". It is noteworthy that using this technique, any inaccurate statement could be claimed to be accurate.

In the 1791 paper, when admitting that the result could be pure water "if there be a redundancy of inflammable air in the process", he now argued that the principle of acidity that was in the dephlogisticated air and the phlogiston that was in the inflammable air could form the phlogisticated air that was residual in the experiment $(1791$, p. $221 ; 1796$, 52). His (1791, p. 220) overall argument was now that "it is very possible that the pure water that we find may be nothing more than the basis of the two kinds of air, and the principle of acidity in the dephlogisticated air and the phlogiston in the inflammable air, may combine to form a superfluous acid in the one case, and the phlogisticated air in the other".

Maclean in his Two lectures pointed out, among other objections, that Priestley was not taking into account Séguin's (1791, p. 48) identification that there was a temperature cutoff point below which nitrous acid was not formed (Maclean 1797, p. 42), ${ }^{33}$ and the confirmation of this by Pelletier and Jacquin (Berthollet 1791, p. 140) and van Marum (1792, p. 139). Maclean also pointed out Séguin's (1791, p. 35) identification that the additional phlogisticated air in the French experiment was due to imperfect exhaustion of the vessels (Maclean 1797, p. 43), and that Priestley was not actually testing his gases, so that the azote in his experiment probably arrived in his oxygen gas (Maclean 1797, p. 47).

Priestley countered "that phlogisticated air can be produced from the same materials from which I get nitrous acid, viz. dephlogisticated and inflammable air, I have given various and sufficient proofs" (1797, p. 36). This was another version of his all-purpose rhetorical technique for claiming without evidence that an inaccurate statement was accurate. Priestley continued to argue that the Lavoisians "do not deny that they had a surplus" of phlogisticated air (1797, p. 34) and that the Lavoisians in their experiment had produced more phlogisticated air "than they could well account for. This quantity, therefore and perhaps something more (since the operators were interested to make this as small as possible) must have been formed in the process" $(1800$, p. 44). These claims continued not to take into account Séguin's actual explanation.

Priestley quoted Berthollet and Fourcroy's (1798, p. 306) identification that "the small quantity of acid which is commonly found in this process comes from the azote, which is mixed with the gas", but Priestley (1800, p. 44) argued that "if this was the case, they could never get water free from acid, because they can never wholly exclude azote". This did not take into account Priestley's own (1791, p. 217) admission that he could obtain pure water from the experiment, as well as continuing not to recognise the explanation produced by Séguin, following Cavendish, that the remaining phlogisticated air had been due

33 This point only repeated Cavendish's (1784, p. 134) earlier conjecture of the same process. 
to imperfect exhaustion of the vessels prior to use for the experiment or due to impurities in the original dephlogisticated air.

\section{The question whether or not water is decomposed}

Priestley (e.g. 1785a, pp. 284-289; 1786, pp. 126-127) had interpreted the experiments that he done prior to 1787 on the combination of dephlogisticated air and inflammable air as showing that it was water that was produced. For example, he (1786, pp. 139-142) burned together dephlogisticated air and inflammable air (from iron and oil of vitriol) and he produced water that was "perfectly free from acid". ${ }^{34}$ This implied that water was a compound. Priestley (1788a, p. 147) stated that he had never been able to find any acid in the liquid resulting in his previous experiments of this type. In making the U-turn that he now always found nitrous acid, which he used to support his view that water was not decomposed, he (1788a, p. 147) argued that previously he must not have taken sufficient precautions.

Yet as has been already noted, by 17 August 1788 he was able to produce either water or an acid vapour "at pleasure". By contrast, in public he $(1789$, p. 7$)$ continued to argue that "when the experiments were conducted with due attention" he "never failed... to produce some acid", and in his subsequent letter to Wedgewood of October 1790 (Bolton 1891, p. 103), Priestley took this official line. In his 'methodized' volumes, he (1790c, p. 546) continued to argue that "in what manner soever dephlogisticated air and inflammable air be made to unite, they compose some acid and in no case pure water".

At this stage Priestley became aware of the experiments of Van Troostwyck and Deiman (1789) in which they produced dephlogisticated air and inflammable air separately from water by electricity. Priestley's (1790c, pp. 543-544) "general reply" to these was outstandingly noteworthy. He started by arguing that "it must be acknowledged that substances possessed of very different properties, may, as I have said, be composed of the same elements in different proportions, and different modes of combination". He then noted that "it cannot therefore be said to be absolutely impossible but that water may be composed of these two elements, or of any other", ${ }^{35}$ but argued that "in what degree it contains [these principles], we cannot tell". Once again, this was an all-purpose rhetorical device that could be used to argue a case against any accurate evidence. Priestley went on to modify, if not to abandon, his argument that water was not composed or decomposed by arguing that "this is no argument against the doctrine of phlogiston, since it only proves that this principle is contained in water, more or less intimately combined, as well as in many other substances". In Priestley's view, he had now replied to Van Troostwyck and Deiman, until he could repeat their experiments more conclusively.

When he (1791, p. 217) reported that "I am now able to procure, either nitrous acid or pure water, from the same materials. I constantly observe, that if there be a surplus of dephlogisticated air, the result of the explosion is always the acid liquor, but if there be a surplus of inflammable air, the result is simply water", he (1791, p. 219) also stated "I claim no merit whatever in this observation". In effect Priestley was repeating Cavendish's

\footnotetext{
34 Priestley (1783, p. 427) also found water produced when his inflammable air came from charcoal: in that case the dephlogisticated air came from nitre and both gases were stored over mercury and fired by electricity: he found "a manifest deposition of water".

35 The last of these italics have been added for emphasis.
} 
(1784, pp. 136-137) observation concerning how water could be produced in the experiment. Whereas Cavendish had given reasons for the difference, Priestley (1791, p. 220) was "by no means able to assign any reason for this difference".

Priestley (1791, pp. 213-214) repeated the back-up argument that he had already used concerning the experiments of van Troostwyck and Deiman, that the doctrine of phlogiston would "not be affected by the most decisive proof of the composition of water from dephlogisticated air and inflammable air, since this would only prove, that phlogiston is one constituent part of water, which is an opinion that I have advanced, and mentioned on several occasions". Priestley also departed from his water-as-element view as well as his view that dephlogisticated air and inflammable air did not form water, by stating that he (1791, p. 219) "concluded that nitrous air, though consisting of the same elements with pure water ${ }^{36}$ contains a greater proportion of dephlogisticated air". In 1791, therefore, he abandoned his (1788a, p. 154; 1790c, p. 535) central argument that water was not composed or decomposed.

In Priestley's (1793) paper on the generation of air from water, he (1793, pp. 33 and 36) said that he "could not help concluding that the whole of any quantity of water is convertible into air by means of heat". ${ }^{37} \mathrm{He}$ made a wide inferential leap to the view that "the whole of the atmosphere may have been originally formed from water by means of heat" (1793, p. 36). A second inferential leap led him to conclude that "since the atmosphere consists of both dephlogisticated air and phlogisticated air, it is evident... that... water must contain both these elementary ingredients, which is an idea which neither myself nor the French chemists had formed of it, since, according to them, it consist of dephlogisticated air and inflammable air, and phlogisticated air (or, as they call it, azote) is a simple element not contained in water, while I and other chymists had considered water as a simple elementary substance" (1793, p. 37). He qualified his new conclusion by arguing that "what I have before advanced concerning water,... viz. that it is the proper basis of every kind of air, may be, and probably is, strictly true" (1793, p. 37). This resulted in the compositional circularity that dephlogisticated air and phlogisticated air were constituents of water which was a constituent of each of them.

However, when producing his later polemics, he once again ignored his (1791, p. 219; 1793, p. 37) arguments that water was a compound. To Mitchill's (1798) attempt to produce a compromise between the systems, Priestley (1798) replied that "in my opinion there can be no compromise between the two systems... water is either resolvable into two kinds of air, or it is not", when supporting the latter position.

Concerning Van Troostwyck and Deiman's experiments using electricity to produce dephlogisticated air and inflammable air from water, Priestley (1800, p. 54) now stated that the two airs were produced from water in these experiments, "tho' with infinite labour". He now objected that the experiment was "very complex" and continued to argue that "several agents are concerned, and what, and how much, to ascribe to each of them it is not easy to say". He continued to state that in his own experiment the last air produced from water was

\footnotetext{
36 Italics added for emphasis.

37 This did not lead him to question if collecting his airs over water in the experiments reported in his (1791) paper had left his airs as pure as he had argued, which had been the basis for his (1791, p. 221) argument that he had proved that the nitrous acid in that experiment was not due to the presence of phlogisticated air.
} 
"wholly phlogisticated air, ${ }^{38}$ of the nature of which we know but little". He also argued that the combination of the two airs being "sometimes spontaneous, without the electric spark being taken in them, shews that at least part of the air produced is phosphoric; and it is well known that the electric spark is always accompanied by the smell of phosphorus". He also stated that he did not see how it was possible to conduct the experiments with only water involved. ${ }^{39}$ Once again, given this repertoire of rhetorical techniques, he could argue that any accurate experimental evidence was inaccurate as well as the reverse.

Despite all his U-turns, inconsistent arguments and use of rhetorical techniques that have been outlined in this sub-section, he (1802, p. 154) argued that he considered that the modern hypothesis of the decomposition of water was "wholly chimerical".

All the details that have been given in this section now allow Priestley's polemical claims against Cavendish and the antiphlogistians to be assessed in the next section in the light of a detailed understanding of his own practices in his late work and polemics in chemistry.

\section{Priestley's polemical claims in the light of his own practices}

This section will assess each of Priestley's claims that have been summarised in the Introduction. Firstly, he argued that "I cannot help thinking that what I have observed in several of my former publications has not been sufficiently attended to, or well understood" (1800, p. 3). Yet in the cases of water and related airs, Cavendish and Lavoisier had achieved a very detailed understanding of the experiments, the needs of the apparatus, the methods of reducing the amount of impurities in the apparatus, and the methods of achieving a result of pure water despite the presence of impurities in the airs and apparatus. Very detailed attention had been paid to the problems of Priestley's experiments, especially by Berthollet, Rupp, Woodhouse, and Maclean, who had pointed out among other matters that Priestley had not sufficiently well attended his own previous work as well as to the work of Cavendish. Priestley never recognised the part of Cavendish's (1784, pp. 138-139) work which directly invalidated his (1788a) theory.

He argued that he had not seen "sufficient reason to change my opinion" (1800, p. 2). Yet in view of the array of rhetorical techniques which he could use to argue that any inaccurate result of his own was accurate and that any accurate result of the antiphlogistians was inaccurate, he would never have seen sufficient reason to change his opinion.

He claimed that his apparatus "was perfectly simple, so that nothing can be imagined to be less liable to be a source of error" (1800, p. 48), but the very numerous problems of his apparatus, which were pointed out to him by the antiphlogistians, have been explored in the previous section. He argued that the apparatus of the antiphlogistians "does not appear to

\footnotetext{
38 Priestley (1796, p. 22). Murray (1819, v. 2, pp. 126-144) summarised a large amount of work on the gases contained in water. Gay-Lussac and Humboldt affirmed in 1805 that when air was disengaged in successive portions from water by heating and boiling, the latter portions contained more oxygen than the former.

39 Despite Priestley's protests, work on the subject progressed rapidly and did not support Priestley's quoted points. Davy (1807) stated that "hydrogen, the alkaline substances, the metals, and certain metallic oxides, are attracted by negatively electrified metal surfaces; and... oxygen and acid substances are attracted by positively electrified metal surfaces", and his (1807) experiments showed clearly that substances were transferred even between separate vessels via moistened asbestos fibres, which demonstrated that transmission was indeed happening in the water between the poles.
} 
me to admit of so much accuracy as the conclusion requires, and there is too much of correction, allowance and computation in deducing this result" (1800, p. 44). However Priestley (1788b, pp. 323-330) had been happy to publish Keir's estimate of the quantity of acid present in Priestley's resulting liquid, which involved correction, allowance and computation, and which was inaccurate by a far greater percentage than the Lavoisians' result.

Priestley (1800, p. 50) argued that his apparatus had the advantage that it was "less operose and expensive" than that of the French chemists. However, Cavendish's eudiometer which he used for his experiments, and another apparatus designed by van Marum (1792, p. 114), were less difficult and expensive than Meusnier's (Lavoisier et al. 1783b). Van Marum's detailed report on his apparatus was sent to Berthollet and quickly published in the Lavoisians' journal, Annales de Chimie. ${ }^{40}$ More generally, simplicity and lack of expense were advantages in experiments if and where the variables involved in the experiment were being adequately tested, but not otherwise.

Priestley claimed that "no person who has made near so many experiments as I have, has made so few mistakes" (1800, p. 4). The evidence concerning his experiments from 1783 onwards on water and related airs suggests that few persons have ever made so many experimental and interpretational errors, so many loose judgements, so many U-turns and so many purely rhetorical rejections of valid criticisms on a single type of experiment, as Priestley.

He (1800, p. 44) argued that the Lavoisians had only made one experiment in which the result was free of acid, and that this was an inadequate basis for generalisation. This did not take into account that Cavendish $(1784$, p. 133) had identified the general correlations that showed how to produce results involving pure water, that the Lavoisians' final experiment had taken these on board as well as their own previous experience, that Séguin (1791) had indicated that the Lavoisians could produce water that was free of acidity at will, and that Priestley (1791, p. 217) himself had stated that he could produce water that was free from acidity at will. ${ }^{41}$

He said to the antiphlogistians that "no man ought to surrender his judgement to any mere authority", and that as "you would not, I am persuaded, have your reign to resemble that of Robespierre, few as we are who remain disaffected, we hope you would rather gain us by persuasion, than silence us by power" (1796, pp. i-ii [33-34]; 1800, p. xi; 1803, p. xiii). Several points need to be made about Priestley's challenge.

Firstly, there was no mechanism by which the antiphlogistians could have silenced Priestley or other phlogistians by power, even if they had wished to. Priestley's articles were welcomed by Samuel Mitchill and frequently appeared in the Medical Repository, they also frequently appeared in Nicholson's Journal, and Priestley's articles were given pride of place in the 1799 and 1802 editions of the Transactions of the American Philosophical Society. In addition, Crell's journal and Observations sur la Physique under de la Métherie continued to welcome articles by phlogistians, when such were forthcoming. By contrast the reason it had been necessary for the antiphlogistians to establish Annales de Chimie had been the difficulty of getting their articles published by the hostile de la Métherie. Also, Priestley's works on science generally sold well, and he had always found

\footnotetext{
40 Priestley's later publications show that he obtained and read the Annales de Chimie quickly, even when he was in America.

41 As has already been noted, Priestley had also previously produced water that he stated was acid free (1786, pp. 80-85, 126-127, 139-142) even though he later disclaimed these statements by saying that he had not taken sufficient care with the experiments.
} 
a publisher or printer, even in the cases (e.g. 1788c, d) where his religious subject matter was of such limited interest to the book-buying public that he had to pay for the edition himself.

Secondly, although Priestley argued that "no man ought to surrender his own judgement to any mere authority, however respectable", this did not stop him $(1800, \mathrm{p}$. vi) from citing the names of Crell, Westrumb, Gmelin and Meyer when stating that "no person needs to be ashamed of avowing an opinion which has the sanction of names such as these". Berthollet and Fourcroy $(1798$, p. 309) said that Priestley would undoubtedly be pleased to hear that in France, de la Métherie, Sage and Baumé were also phlogistians, as well as other chemists of lesser rank, but Priestley (1800, p. vi) argued that there were fewer remaining phlogistians in France than in England. Thirdly, Berthollet's (1789) and Berthollet and Fourcroy's (1798) articles argued that Priestley's experimental methods and his interpretations of his experiments had been flawed, not that he should not hold independent opinions.

Fourthly, in practice Priestley had an asymmetrical view of intellectual authority. On the one hand Priestley (1794, p. ix) rejected the intellectual authority of others to the extent of saying that educational institutions were not to be regarded as sources of information. However, on the other hand Priestley did not avoid asserting the rectitude of his own positions. For example, he asserted that his type of materialism "is that philosophy which alone suits the doctrine of the Scriptures,... every other system of philosophy is discordant with the Scriptures" (1777, p. 302), and he (1803, p. vii) took the triumphalist and illiberal position that he had produced "a demonstration of the doctrine of phlogiston and a complete refutation of the composition of water", and proposed that the Lavoisians' theory should be abandoned altogether (Priestley 1803, p. xviii). ${ }^{42}$ In effect, Priestley protested at any restriction to his own way of thinking while sometimes proposing that others should follow his own opinions.

Fifthly, Priestley's own language could be remarkably unpersuasive, especially when he argued that he was being persuasive rather than using force, for example when he (1787, 17) argued with the Prime Minister, Pitt. He $(1787,41)$ referred to Pitt as a "youth" and (1787, p. 2) stated that Pitt had been "misled by your education and connections". Priestley (1787, p. 1) stated that he was entitled to gratitude in that he was suggesting ideas which appeared to him to be clearer that those that Pitt "seemed to be possessed of". Priestley (1787, p. 3) stated, from his position as an older man than Pitt, that "honesty is the best policy", and admonished Pitt to "keep this in view in all measures of policy". He also used the language of power in that he (1785b, p. 544) stated that the arguments of the Dissenters were like gunpowder and he (1790d, p. 311) predicted that this "gunpowder... which will certainly blow [the system of the hierarchy] up... and perhaps as suddenly... and as completely... as the overthrow of the late government of France". The antiphlogistic responses to Priestley (e.g. Berthollet and Fourcroy 1798) were far more polite and potentially "persuasive" to Priestley than Priestley could be to opponents. Sixthly as has been seen, Priestley's late theory and rhetorical methods allowed him to be effectively immune to persuasion by the usual scientific means of the production of experimental evidence.

All the evidence that has been collected in this and the previous section shows that Priestley's complaints concerning inattention, authority, rule and so on, only seem at all

\footnotetext{
42 If Priestley had been a liberal individualist, he would have developed his own views while accepting that the Lavoisians' theory would also be developed. There was a consistent liberal position to be taken on this issue, but Priestley did not occupy it.
} 
plausible when his own practices in chemistry and in rhetoric are not taken into account in detail.

\section{A brief survey of selected secondary literature}

Some early chemists saw Priestley's late work on water and related airs with clarity. For example, Black stated in his lectures at Edinburgh that "It is... difficult to procure vital air perfectly pure, and, especially, free from azote. The red nitrate of mercury affords the best process I know for it. But I have generally found it tainted with nitrous air, and with azote. I call your attention to this circumstance, because many of Dr. Priestley's experiments, by which he still thinks that the theory of Stahl is supported, have had results which were certainly owing to such impurities. I have particularly in my eye at present those which he published in 1792". 43

Thomson (1830, v.2, p. 22) argued that Cavendish's (1784) facts concerning nitrous acid in the experiment "invalidate the reasoning of Priestley altogether; and had he possessed the skill, like Cavendish, to determine with sufficient accuracy the proportions of the different gases in his mixtures, and the relative quantities of nitric acid formed, he would have seen the inaccuracy of his own conclusions". More generally, Thomson (1830, v. 2, p. 137) judged that "Dr. Priestley... was so hasty in his decision, and so apt to form his opinions without duly considering the subject, that his chemical theories are almost all erroneous and sometimes quite absurd". This judgement is amply borne out by the evidence in the present paper. It is interesting that Thomson's view can be seen as in conformity with some of the types of judgement Priestley made concerning opponents' work.

Partington (1962, pp. 270-271) stated about the late work that "Hartog says 'Priestley henceforth displays what seems to us a perverse ingenuity in adapting the phlogiston theory to fit every new fact' and it would be tedious to follow him through this labyrinth of error", and Partington (1962, p. 293) judged that "Priestley's later papers... are of little or no interest and are mostly inaccurate". The present paper has illustrated quite how accurate was the description "labyrinth of error" for Priestley's late work on this topic.

Holmes (2000, pp. 91 and 93) noted the "typical pitfalls that Priestley's casually stated 'opinions' on the composition of the airs which he studied set for his followers. When enthusiasts such as Volta tried to fill in the details left unexplored in the lapidary formulations of their leader, they were easily led into contradictions hidden from them by their allegiance to Priestley's general 'doctrine of airs'". Holmes (2000, p. 99) pointed out that Priestley actually had a "casual attitude toward the 'speculations' that he allowed himself while insisting that it was really only the 'facts' that counted". Holmes (2000, p. 103) stated that "Historians as well as contemporaries have generally been sympathetic to the personal credo that Priestley stated so strongly... He appears open-minded and democratic, committed to a kind of science in which everyone can participate and no one has particular authority. But... Priestley was professing principles that he did not in fact fully practice....

\footnotetext{
43 The publication of Black's lectures occurred after his death, and this quote $(1803$, p. 541) will actually date from between 1792 and 1797 when Black ceased lecturing. Priestley's (1791) paper was given in April 1791, so it was included in the second volume of the Transactions which generally went to press in November, and so 1792 will be when Black received Priestley's (1791) paper.
} 
Priestley was flexible only within the limits of the broad 'modern doctrine of airs' that he had initiated", ${ }^{44}$ and this is amply justified in the case of Priestley's later theory on water.

An attempt to explain Priestley's defence of phlogiston was made by Verbruggen (1972), but this had numerous problems of which the following are arguably the most noteworthy. Verbruggen (1972, pp. 47-50) gave prominence to Priestley's (1791) paper and Lavoisier's 1785 experiment. This is a historical error since Priestley's paper came after the Lavoisians' later and corrected large-scale experiment (Lavoisier et al. 1790), to which Priestley (1791) specifically referred. Verbruggen also did not take fully into account Cavendish's $(1784,1785)$ work and did not take into account the rhetorical nature of several of Priestley's claims.

Verbruggen (1972, p. 48) effectively altered the implication of Black's remark by suggesting that Black thought that Priestley's use of impure chemicals was the direct cause of his adherence to the theory of phlogiston. One of Verbruggen's (1972, p. 52) central arguments then was that the acidity in both the experiments of Lavoisier and Priestley was due to impurities. However, firstly this misconstrued Black's remark, which suggested that Priestley's argument that his experiments supported his theory was incorrect due to impurities, not that impurities caused Priestley's adherence to the theory of phlogiston. Secondly, Cavendish's $(1784,1785)$ findings solved the problem with Lavoisier's (1785) experiment ${ }^{45}$ and the Lavoisians' et al. (1790) experiment was free from acid, while one of Cavendish's (1784, pp. 138-139) findings was directly contrary to Priestley's theory, and Priestley never acknowledged or solved this problem. Verbruggen (1972, p. 48) also did not take into account that Priestley's (1788a, b, 1789) papers resulted in several objections which were based on Priestley's failure to take into account Cavendish's careful experimental work.

Verbruggen (1972, p. 54) argued that the Lavoisians procured oxygen that was "quite pure and free from nitrogen". However, in the full report of the later version of their experiment they stated that they wanted to obtain pure vital air, and took several precautions including driving off the atmospheric air in the apparatus before filling with the vital air and also letting go the first products from the calx that they used (Fourcroy et al. 1791, pp. 267-268), but they also stated that they actually produced $97 \%$ pure vital air, with the remainder being azote gas (Séguin 1791, p. 35). Verbruggen (1972, p. 54) then noted that on conclusion, the container in which the combustion had taken place contained carbonic acid and azote gas as well. However, Séguin (1791, pp. 35-36) stated that the excess of measured total gas from the output over the measured input gas was very probably due to the small quantity of atmospheric air which remained in the gasometers, after exhaustion and before filling with the vital air and hydrogen gas, and that it was almost impossible to exclude impurities altogether. All this was in direct agreement with Cavendish's (1784) statements on the impossibility of full exhaustion of the chambers before filling with the intended airs and on the impracticability of obtaining totally pure input airs.

Verbruggen (1972, p. 49) quoted Priestley's (1791, p. 215) argument that his dephlogisticated air contained "no sensible quantity of phlogisticated air". Verbruggen did not take into account the frequent drastic variations in Priestley's reports concerning the degree of purity of his dephlogisticated air, including his (1789, p. 11) admission that phlogisticated air "could not be excluded, whether it was by that which remained in the

\footnotetext{
44 Holmes (2000, p. 76) argued, "Priestley has often been treated more kindly than Lavoisier".

45 Verbruggen (1972, p. 52) did not recognise this, which led to his claim that it was "surprising" that while the occurrence of acidity flagged up to Lavoisier as a problem by the Duc de Chaulnes on 6 March, the matter was apparently not discussed at the meeting with the Duc and others on 7 March.
} 
vessel after exhausting it by the air pump, or that with which the dephlogisticated air was more or less contaminated", nor that there was no practicable way that he could have produced dephlogisticated air of the degree of purity that he claimed in 1791 .

Verbruggen (1972, pp. 48-49) then suggested that in order to "refute" the argument of the Lavoisians, Priestley argued that an increase in the quantity of the phlogisticated air in the experiment produced a decrease in the acid formed. However, firstly this did not take into account that it was Cavendish who had originated the experimental findings that were crucial to the case, and that he (1784, pp. 133-134) had identified that when there was much phlogisticated air present, an increase in its quantity produced a decrease in the acid formed, but (1784, pp. 138-139) when the dephlogisticated air was relatively pure the introduction of phlogisticated air increased the amount of acid, and Priestley never acknowledged the latter finding. Also, Cavendish and the Lavoisians were effectively in agreement on this and had been so since 1785, so that this was not a distinction between phlogistic and antiphlogistic theories, but one between Priestley's view and those both of a phlogistian and of the Lavoisians who each conducted this particular type of experiment with apparatus that allowed for identification of more parameters and for greater accuracy.

Verbruggen (1972, p. 48) also quoted Priestley's argument that if any quantity of nitrogen was combined with oxygen or hydrogen, the combustion proved to change neither the quantity nor the quality of the nitrogen involved. However, Priestley (1791) was producing his airs directly into the chamber in which he made the explosion, so that the apparatus did not involve any method of checking the quantity or quality of the phlogisticated air that was initially included or eventually present. His rhetoric continued not to take into account Cavendish's (1784, pp. 133-134, 138-139) careful prior findings as to the changes that were produced by differing amounts of initial nitrogen.

Verbruggen (1972, p. 49) quoted Priestley's (1791) argument that in the case of a surplus of hydrogen, nitrogen was produced. This did not take into account his (1789, p. 11) admission that phlogisticated air "could not be excluded, whether it was by that which remained in the vessel after exhausting it by the air pump, or that with which the dephlogisticated air was more or less contaminated". Verbruggen did not recognise that since 1789 Priestley had changed the colour of the mercury calx from which he extracted his dephlogisticated air but apparently not any of his methods for doing so, that there was no way of extracting residual phlogisticated air from incoming dephlogisticated air, and that Priestley had changed his apparatus in such a way as to introduce a new way in which phlogisticated air could enter the chamber.

Verbruggen (1972, p. 49) quoted Priestley's (1791) indication that if there was an excess of excess of inflammable air, pure water was produced, without noting that Cavendish (1784, pp. 135-136) had previously published this, and that Priestley $(1789$, p. 7; 1790a, p. 546) had been continuing to maintain in published work that he never failed to produce an acid. It was only Priestley's awareness of the new experiment by the Lavoisians et al. (1790) that in effect impelled him to publish that he could form pure water in this experiment at will.

Verbruggen (1972, p. 50) then stated that it would be obvious to the reader that Priestley's view of the formation of nitrogen and nitrous acid was due to his use of impure oxygen. Verbruggen appears to be referring to the modern reader, but the more important issue is that it was also obvious to a contemporary reader who had read Cavendish's (1784) paper with full attention, or read Berthollet's (1789) paper, or any of the papers about the Lavoisians' et al. 1790 experiment (1790; Fourcroy et al. 1791; Séguin 1791). Kirwan, who did undertake a "reflective reading" of Berthollet's (1789) paper, cited it as one of his 
reasons for giving up phlogiston (in Lavoisier 1997, p. 227), and cited the Lavoisians' et al. 1790 experiment as another reason (Kirwan 1791).

Verbruggen (1972, p. 66) argued that Priestley's observations were no less accurate than those of Lavoisier and the other antiphlogistians, with regard to "the perception and description of all phenomena that make up a chemical reaction." This is a drastic misrepresentation of the situation, which was that Cavendish has produced the most accurate perception and description of the phenomena, and that the Lavoisians et al. (1790) experiment had followed Cavendish's findings, while Priestley had continued not to recognise Cavendish's (1784, pp. 138-139) finding that disconfirmed Priestley's theory, and had produced a "labyrinth of errors".

Schofield produced statements about this period of Priestley's output on several occasions. He (1964, p. 289) wrongly stated that "the experiments of Priestley, of Cavendish and of Lavoisier and his adherents report that an acid was obtained, not simple water", and argued that "Priestley, the brilliant experimenter, was totally unable to ignore this production of acid". Schofield (2004, p. 183) took at face value Priestley's repeated statements that the more phlogisticated air he added to the pure and inflammable airs, the less acid he obtained, and went on (2004, p. 192) to argue that "failure to take [Priestley's] experiments seriously reveals a major flaw in the new chemistry, for the experiments did not simply reveal an acid, they showed that the amount of the acid was to be controlled not by elimination of an impurity but by its deliberate introduction... or by slow combustion rather than explosion" and that "this solution was unavailable to the new chemistry". However, these arguments have all the problems that have already been identified concerning Verbruggen's version of the matter, and also did not take into account that the Lavoisians knew of Cavendish's findings concerning the experiments by the end of May 1785, and that these solutions were represented in the papers produced by the Lavoisians on their revised experiment in $1790-1791,{ }^{46}$ so that all this was indeed taken into account in the new chemistry. Furthermore, Schofield did not take into account Berthollet's (1789) arguments against Priestley's (1788a, b, 1789) papers. $^{47}$

Schofield (2004, p. 190) commented that Priestley's (1791) "paper had little influence on the growing acceptance of the 'new chemistry', nor did any paper by Priestley from now on". Schofield provided the explanation that the Nomenclature (Guyton de Morveau et al. 1787) and the Traité (Lavoisier et al. 1790) had now been published, the Annales de Chimie had started to appear, and the new chemistry was now established. However, there are also crucial points that are directly related to Priestley's work. The Lavoisians could see that Priestley was several years behind Cavendish and the Lavoisians in terms of understanding the problems of the experiment, and when Berthollet (1789) told him this in detail, Priestley did not actually answer many of Berthollet's points, but began to parry criticisms with rhetoric, as has been illustrated in previous sections of the present paper, and this was not recognised by Schofield.

Schofield (2004, p. 368) argued that Priestley "had no coherent system to substitute for the one he felt was inadequate", which was one main reason why his "attacks on individual experiments were futile". This was not fully correct: Priestley (1794, pp. 8-9) did have what he called a "theory, or system of principles", and Priestley continued to argue that his system was preferable to that of the Lavoisians. Priestley's attacks on individual

\footnotetext{
${ }^{46}$ Lavoisier et al. (1790), Fourcroy et al. (1791) and Séguin (1791). These were not included in Schofield's (2004) bibliography.

47 Schofield's (2004) bibliography also does not include Berthollet (1789).
} 
experiments were indeed futile, as Schofield rightly pointed out, but this was because of the extreme problems of his late work which have been illustrated in the present paper.

McEvoy (1990, p. 133) argued that Priestley's debate with the Lavoisians was influenced by a set of philosophical principles arising out of the synoptic unity and interaction of epistemological, metaphysical, methodological theological and strictly scientific parameters in his thought. The inaccuracies of this are being demonstrated in a separate paper. McEvoy (1990, p. 133) also argued that "the empirical adequacies of the competing theories have been virtually equivalent", but the inaccuracies of this have been demonstrated (Blumenthal and Ladyman 2017b) as well as in the present paper. He did not modify these claims in the light of his (1990, p. 139) admissions that Priestley's (1786, pp. 7-8) identification of phlogiston with inflammable air was "a simple experimental error", and that Priestley's (1788a, p. 156) claim that phlogiston had weight and perfectly corresponded to the definition of a substance was also untenable. Priestley later argued that phlogiston might or might not have weight depending on which of these suited his argument at the time. McEvoy (1990, pp. 141-142) supported Priestley's claim that both theories had difficulties, but the major differences between the new chemistry and the many phlogistic theories have been demonstrated (Blumenthal and Ladyman 2017b) as well as in the present paper.

Conlin (1996, p. 129) claimed that "historians have generally found Priestley's defence of phlogiston not only to be rational but also to be meritorious in various ways" without giving references. Yet even writers such as Cooper (in Priestley 1806), Jeffrey (1806) and McEvoy (1990) have tended include very little on his defences of phlogiston and have chosen to emphasise his attacks on the antiphlogistians' theory. Conlin (1996, p. 129) inaccurately claimed that Priestley "converted antiphlogistian James Woodhouse to phlogiston theory", which is disconfirmed in great detail by Woodhouse's (1799) actual work. Conlin made the (1996, p. 130) lesser claim that Woodhouse only "accepted a part of Priestley's phlogiston theory", but Woodhouse (1802) effectively abandoned only the specific hypothesis by Berthollet that heavy inflammable air was carbonated hydrogen, while noting Cruickshank's (1801) actually correct indication that it was an oxide of carbon containing half as mixed oxygen as carbonic acid (fixed air). Woodhouse (1799, pp. 465-466) had indicated that Priestley's hypotheses on finery cinder and heavy inflammable air were "very unsatisfactory", so it is incorrect to say that Woodhouse accepted part of Priestley's phlogiston theory. Even Priestley (1803, p. xviii) only stated that Woodhouse abandoned one part of the new theory. Conlin (1996, p. 129) gave the blanket argument that "Priestley was an inductive empiricist", but this does not apply to the basic views of the late theory. Conlin (1996, p. 129) argued that "Priestley graciously sent the antiphlogistians accounts of experiments which favoured phlogiston theory", but as the present paper illustrates, Priestley's experiments did not actually support his phlogistic theory.

Chang (2012, p. 5) argues that Priestley "published well-informed and closely reasoned defences of phlogiston", but some of the many problems of this judgement are outlined in the present paper. Chang (2012, p. 7) argues that "historically well-informed philosophers have struggled to say exactly what was wrong with Priestley's stance, but the enormous number of problems with Priestley stances and work in chemistry have been illustrated in the present paper and other papers (Blumenthal and Ladyman 2017a, b). All these matters are examples why Chang's recommendation of normative pluralism for chemistry is not supported by late eighteenth-century chemistry.

There is a very large number of problems with Crosland's (1995) attempt at a social constructionist defence of Priestley. Crosland (1995, p. 110) argued that "as a plain Englishman [Priestley] often said that he was concerned only with the facts". However, another 
plain Englishman, ${ }^{48}$ Cavendish (1784, pp. 133-134, 136-139), had determined facts which showed the errors of Priestley's $(1788 \mathrm{a}, \mathrm{b}, 1789,1791)$ later views, of which Priestley did not recognise the one which was crucial. Priestley from 1783 onwards is more reasonably characterised as a controversialist who was primarily concerned to win an argument according to his own criteria, irrespective of how many "facts" he discarded in the process.

Crosland (1995, p. 106) argued concerning Priestley that "it was the low cost of the basic apparatus of pneumatic chemistry which had been a major factor in attracting him to this field of science", (1995, p. 109) that Priestley "must have seen Lavoisier as very elitist, and in more ways than one" and $(1995,116)$ that "in any case, long drawn-out quantitative experiments were just not Priestley's style". Yet Priestley's own theory concerning the result of the experiment resulted in the need for apparatus and initial substances that would totally exclude impurities, which was far more impracticable than merely competing with Cavendish's and Lavoisier's apparatus. The numerous problems of his apparatus and initial substances were pointed out to him on numerous occasions, but he chose to parry these valid criticisms by rhetorically asserting the superiority of simple, cheap apparatus. It was and remains a mistake to assume that cheap apparatus and Priestley's own experimental style could be used satisfactorily, irrespective of the nature of the problems, and irrespective of the unique level of experimental difficulties which was caused by Priestley's own theory.

Crosland (1995, p. 109) argued that "the two chemists belonged to contrasting traditions. They viewed the natural world and society from completely different standpoints" and ((1995, p. 116) that "It was not so much that Priestley complained about the expense of Lavoisier's apparatus as that it belonged to a different world". However, it is more accurate to say that where experiments were concerned, Cavendish and Lavoisier belonged to the usual empirical tradition in which what mattered was finding out about the world, while Priestley belonged to a different "world" in which what actually mattered was not the ostensible aim to understand the chemistry but the underlying aim to "win" an argument in Priestley's style of controversy.

Crosland (1995, p. 106) argued that "Priestley, like so many adherents of the phlogiston theory, thought of chemistry as a qualitative science". However firstly, as Rodwell (1868, p. 30) pointed out, the phlogistians were aware of the weight issue but "generally omitted [it] from their handbooks". It was extremely difficult if not impossible to maintain a phlogistic theory and deal with weight considerations, so the simplest solution was not to deal with weight considerations. Secondly, the phlogistian Cavendish performed excellent experiments at this period using quantitative volumetric measurements, which resulted in the crucial understanding of several variables concerning this experiment.

Crosland (1995, p. 104) argued that "The French chemists seemed not to treat their opponents as equals but rather as misguided or even stupid colleagues, who failed to see the significance of the new evidence". Yet the "French chemists" as a whole were not united, as Berthollet and Fourcroy (1798) pointed out to Priestley, and the antiphlogistians treated their "opponents" on scientific merit, being very respectful of Cavendish's "beautiful experiments" 49 and treating Priestley with the respect due to his early work. Berthollet's (1789) prime arguments were that Priestley had failed to remember his own previous precautions, as well as failing to see the significance of his colleague Cavendish's work.

\footnotetext{
${ }^{48}$ Cavendish in later life had an enormous income but still lived a very plain lifestyle, as McCormmach's works on Cavendish demonstrate.

49 C.f. Berthollet's letter to Blagden on 17 June 1785, (Sadouin-Goupil 1971).
} 
Crosland (1995, pp. 109-110) argued that "One feature which united Priestley's career in religion, politics and science was his hostility to authority". However, in actuality Priestley was hostile to the supposed authority of others, even when they did not exercise any such authority, while being perfectly content to assert his own claims to authority, as has been illustrated in the previous section. Crosland (1995, p. 110) argued that "Already in 1790 , reacting to the growing influence of the new theory of chemistry, he advocated "putting an end to all undue and usurped authority in the business of religion as well as of science". Yet this involves a simple mistake, in that Priestley's (1790a, p. xxiii) quote was merely a transcription of his exactly similar (1774, p. xiv) remark, and so it was nothing to do with the new theory of chemistry. In addition, Crosland did not take into account all of Priestley's (1774, pp. xv-xvi; 1781a, b, pp. xv-xvi; 1790a, pp. x, xxvi, xxvii) politicallynon-partisan and non-nationalist remarks about science.

Crosland (1995, p. 109) argued that "Priestley was modest in his claims and language". This does not take into account many statements by Priestley, for example (1775, p. ix) that "I may flatter myself, if it be any flattery, as to say, that there is no history of experiments more ingenious than mine", and that "no person who has made near so many experiments as I have, has made so few mistakes" (1800, p. 4). He also (1803, p. vii) claimed that he had "refuted" the "fallacious hypothesis" of the new chemistry, that this could only be "of great importance to the future progress of science", and removed "a great obstacle to the path of true knowledge".

Crosland's (1995) paper falls into the general category of those which can aptly be characterised in the terms of Kusch (2015, p. 78) as adopting "lock, stock and barrel" Priestley's "actors' sociology".

A far better-supported socially-orientated analysis was produced by Golinski (1994), focussing on Lavoisier's and Meusnier's 1785 version of the experiment, so it is of particular interest what this did not take into account. Golinski (1994, p. 38) did not note that one reason why their experiment was not decisive was that a small amount of acidity was found ${ }^{50}$ However, the occurrence of acidity had been explained and two methods of avoiding the acidity had been given by Cavendish (1784). This paper had very recently been published in French, after the final preparations for Lavoisier's and Meusnier's experiment were under way. ${ }^{51}$ It can be inferred that this was where the Lavoisians found the answer to the problem, in that Berthollet's letter to Blagden on 19 March 1785 (Duveen and Klickstein 1954, p. 60) stated that Lavoisier now wished to repeat the experiment by burning dephlogisticated air in inflammable air, in accordance with the "beautiful observations" of Cavendish. Golinski (1994, p. 38) suggests that Lavoisier's experiment convinced Berthollet, but this letter illustrates that Berthollet was influenced by two sets of experiments, those by Lavoisier and Cavendish. It can be inferred that it was also crucial to Berthollet that the results of these experiments added to the increasing difficulties that he had experienced from 1776 to 1782 in attempting to adapt a phlogistic theory to the increasing amounts of available experimental evidence, as will be demonstrated in a separate paper. Golinski did not cover the repetition by the Lavoisians of the large-scale experiment with crucial amendments in 1790, which solved the problem with acidity. As noted above, the 1790 experiment was cited by Kirwan in 1791 as one of the several major reasons why he

\footnotetext{
50 It can be inferred that Lavoisier had not expected to find this, in that the Duc de Chaulnes asked Lavoisier by letter on 6 March to explain the acidity (Lavoisier 1986, pp. 77-78).

51 The first part of the French translation by Pelletier was published in December 1784 and the second part in January 1785 in Observations sur la Physique.
} 
had changed theory, the others being his own failure to demonstrate that the combination of dephlogisticated air and inflammable air could form fixed air, a "reflective reading" of Berthollet's criticisms of Priestley's experiments, and Guyton's article on Air in the Encyclopédie Méthodique (Lavoisier 1997, p. 227; Kirwan 1791).

As Golinski (1994, p. 30) rightly noted, the accumulation of supposed "facts" caused confusion and the ramification of discussions into more and more areas. A lack of concern about linkage between views on different facts underpinned Cavendish's (1784) view that his set of phlogistic hypotheses explained the phenomena at least as well as the new chemistry (Blumenthal and Ladyman 2017a). Golinski does not note that this conviction began to fall apart after Cavendish's (1785) experimental work on the formation of nitrous acid using dephlogisticated and phlogisticated air, which showed that nitrous acid could not be produced when using only phlogisticated air, ${ }^{52}$ as has been noted in the Introduction to the present paper.

Golinksi (1994, p. 32) argued that "Priestley articulated a radically different form of scientific practice and condemned Lavoisier's supposed accuracy”, but did not undertake any analysis of Priestley's apparatus and his claims to accuracy, which had the extraordinary problems that have been illustrated in the present paper. Also, Priestley's practices included rejecting any inconvenient evidence produced by opponents with the unsupported claim that it resulted from overly complicated apparatus, and supporting theories of his own without evidence as "sufficiently evident". This was indeed a radically different form of practice, but it is questionable whether it can reasonably be called "scientific".

Golinski (1994, p.32) rightly noted that "the controversy was eventually brought to a close, albeit in a prolonged and confused way that deserves further investigation". As had been the case with Berthollet, Kirwan's change followed more than one set of adverse experimental evidence combined with difficulties in developing a phlogistic theory satisfactorily to meet the totality of the new evidence, and it can be inferred that the same was the case with Cavendish's change. The present paper has illustrated that Priestley developed methods of retaining his own views and rejecting any evidence produced by others, and that he was freely able to go on publishing revised versions of his views and did so. He was generally treated with the respect that was due to him for his early discoveries in airs. However, his late views were treated on their merits. In the case of heavy inflammable air, his objection stimulated work which resolved that specific anomaly (Cruickshank 1801; Desormes and Clément 1802), while his late work on water and related airs and his late phlogistic theory were a "labyrinth of errors" of which a large number were pointed out to him by his opponents at the time. Undoubtedly there were intensely social aspects to the conduct of chemistry at this period, yet these were not constitutive of the chemistry itself (references removed for review).

\section{Conclusions}

The analysis in this paper has shown that in Priestley's late work on water and related airs, he put forward a theory to support which his apparatus and initial substances would have needed to exclude impurities altogether. His theory did not take into account the solutions

\footnotetext{
52 Blagden provided this paper to Berthollet, who read it to the Académie on 1 June 1785 , one day before Cavendish (1785) read it to the Royal Society. The French version of this paper was published in August 1785 in Observations sur la Physique, well before the English version.
} 
to the difficulties with the experiment which had been comprehensively understood and published by the phlogistian Cavendish several years previously, and with which the Lavoisians were in agreement. Priestley's interpretations were much looser than those of his selected opponents, he readily and fundamentally changed his interpretations of experiments in order to support the version of his theory that he favoured at the time, his basic compositional hypotheses were unfounded, and he was extremely selective about answering the criticisms of any opponent, especially those of Berthollet and Woodhouse. In replying, he used the arsenal of rhetorical techniques that he had honed in the very wide range of ecclesio-political controversies in which he engaged. ${ }^{53}$ From 1791 onwards, when any objections were received, he produced a new defence of his position, utilising whatever arguments that came to mind when writing, and increasingly not taking into account the actual value of the criticisms by his opponents. Nearly all his criticisms of the Lavoisians on these matters were unfounded, and that this was why his criticisms had relatively little effect.

During this period, the new chemistry developed rapidly, so that textbooks at the time had to be frequently revised and expanded due to all the new discoveries. In contrast, Priestley spent his last fifteen years issuing variations of the same arguments, until finally he had apparently convinced himself that he had won a glorious battle and vanquished the new chemistry. Priestley was among several participants who continued to hold their own versions of a phlogistic theory: others who did so included Crell, Gmelin, Wiegleb, de la Métherie, Sage, Baumé, Cadet, Watt, and Keir. Of these others, de la Métherie was arguably the most prolific in continuing to issue public defences of phlogiston and attacks on the new chemistry. Yet no-one else combined the early prestige of experimental discoveries with well-developed rhetorical expertise and with apparent (and wholly inaccurate) belief in their own victory, in the way that Priestley did.

All this is of much wider importance as an example of how science progresses. In practice, it is not possible to determine scientific theories against all possible counter-theories and arguments. Therefore in the cases of participants who wished to defend a theory irrespective of inconsistency and the lack of testability of their theories, they could do so, as Priestley did. However, this effectively came at the price of entering an infertile backwater in which he made no further progress in chemistry. By contrast in the cases of participants in late eighteenth-century chemistry who were centrally concerned with developing a fertile way forward in chemistry, after much work it became apparent that the best way of doing this was by identifying the available coherent theory that was as experimentally-testable as practicable, and this dealt with the issue of the very numerous ways in which theories could be compared (Blumenthal and Ladyman 2017b). All this has general implications for how experiments, apparatus and theories are chosen and defended, for how future directions of research are chosen, and for some of the problems with some stances in the history, philosophy and sociology of science.

Funding The funding was provided by Arts and Humanities Research Council (Grant No. 1225327).

Open Access This article is distributed under the terms of the Creative Commons Attribution 4.0 International License (http://creativecommons.org/licenses/by/4.0/), which permits unrestricted use, distribution, and reproduction in any medium, provided you give appropriate credit to the original author(s) and the source, provide a link to the Creative Commons license, and indicate if changes were made.

\footnotetext{
53 For these methods c.f. his $(1806$, v.1, pp. 80, 115, 121). His view of "wining" an argument was if his opponents stopped replying to him. In order to bolster this view, he had extremely low expectations of any opponent adopting his views following such a controversy. C.f. also (reference removed for review).
} 


\section{References}

Berthollet, C.-L.: Considérations sur les expériences de M. Priestley. Ann. Chim. 3, 63-114 (1789)

Berthollet, C.-L.: Observations sur le nouveau dictionnaire de chimie de M. Keir. Ann. Chim. 10, 131-147 (1791)

Berthollet, C.-L., Fourcroy, A.-F.: Réflexions sur la doctrine du phlogistique et de la décomposition de l'Eau, par Joseph Priestley. Ann. Chim. 26, 302-309 (1798)

Black, J: In: Robison, J. (ed.) Lectures on the Elements of Chemistry, vol. 2. Mundell, Edinburgh (1803)

Blumenthal, G., Ladyman, J.: The development of problems within the phlogiston theories, 1766-1791. Found. Chem. 19, 241-280 (2017a)

Blumenthal, G., Ladyman, J.: Theory comparison and choice in chemistry, 1766-1791. Found. Chem. (2017b) (online)

Bolton, H.: Scientific Correspondence of Joseph Priestley. Privately printed, New York (1891)

Cavendish, H.: Three papers, containing experiments on factitious air. Philos. Trans. R. Soc. Lond. 56, 141184 (1766)

Cavendish, H.: Experiments on air. Philos. Trans. R. Soc. Lond. 74, 119-153 (1784)

Cavendish, H.: Experiments on air. Philos. Trans. R. Soc. Lond. 75, 372-384 (1785)

Cavendish, H.: On the conversion of a mixture of dephlogisticated and phlogisticated air into nitrous acid, by the electric spark. Philos. Trans. R. Soc. Lond. 78, 261-276 (1788)

Chang, $\mathrm{H}$.: Is water $\mathrm{H}_{2} \mathrm{O}$ ?. Springer, Dordrecht (2012)

Conlin, M.: Joseph Priestley's American defence of phlogiston reconsidered. Ambix 43, 129-145 (1996)

Crosland, M.: Lavoisier, the two French revolutions and 'The Imperial Despotism of Oxygen'. Ambix 42, 101-118 (1995)

Cruickshank, W.: Some observations on different hydrocarbonates and combinations of carbone with oxygen. [Nicholson's] J. Nat. Philos. Chem. Arts 5, 1-9 (1801)

Davy, H.: The Bakerian Lecture: on some chemical agencies of electricity. Philos. Trans. R. Soc. 97, 1-56 (1807)

Desormes, C., Clément, N.: Mémoire sur la réduction de l'oxide blanc de zinc par le charbon, et sur le gaz oxide de carbone qui s'en dégage. Ann. Chim. 39, 26-64 (1802)

Duveen, D., Klickstein, H.: A letter from Berthollet to Blagden relating to the experiments for a large-scale synthesis of water carried out by Lavoisier and Meusnier in 1785. Ann. Sci. 10, 58-62 (1954)

Fourcroy, A.-F., Vauquelin, L., Séguin, A.: Mémoire sur la Combustion du Gaz Hydrogène dans des Vaisseaux clos. Ann. Chim. 8, 230-307 (1791)

Golinski, J.: Precision instruments and the demonstrative order of proof in Lavoisier's chemistry. Osiris $\mathbf{9}$, 30-47 (1994)

Grison, E., Goupil, M., Bret, P. (eds.): A scientific correspondence during the chemical revolution: LouisBernard Guyton de Morveau and Richard Kirwan, 1782-1802. Office for History of Science and Technology, Berkeley (1994)

Guyton de Morveau, L.-B., Lavoisier, A.-L., Berthollet, C.-L., Fourcroy, A.: Méthode de Nomenclature Chimique. CUCHET, Paris (1787)

Henry, W.: Experiments on the quantity of gases absorbed by water, at different temperatures and under different pressures. Philos. Trans. R. Soc. Lond. 93(29-43), 274-276 (1803)

Holmes, F.: Phlogiston in the air. Nuova Voltiana 2, 73-111 (2000)

Jeffrey, F.: Memoirs of Dr. Joseph Priestley. Edinb. Rev. 9, 136-161 (1806)

Kirwan, R.: Vom Herrn Ritter Kirwan in Dublin. Chem. Ann. 1, 425-426 (1791)

Kusch, M.: Scientific pluralism and the chemical revolution. Stud. Hist. Philos. Sci. 49, 69-79 (2015)

Lavoisier, A.-L.: Considérations générales sur la nature des acides et sur les principles dont ils sont composés (1778). In: Oeuvres de Lavoisier, vol 2, pp. 248-260. Paris, Imprimerie Imperiale (1862)

Lavoisier, A.-L.: Mémoire dans laquelle on a pour objet de prouver que l'eau n'est point une substance simple, un élément proprement dit, mais qu'elle est susceptible de décomposition et de recomposition (1783a). In: Oeuvres de Lavoisier, vol 2, pp. 334-359. Paris, Imprimerie Imperiale (1862)

Lavoisier, A.-L.: Description d'un appareil propre à manoeuvrer différentes espèces d'air, dans les expériences qui en exigent des volumes considérables, par un écoulement continue parfaitement uniforme et variable à volonté, et donnant, à chaque instant, la mesure des quantités d'air employées, avec toute la précision qu'on peut désirer (1783b). In: Oeuvres de Lavoisier, vol 2, pp. 432-440. Paris, Imprimerie Imperiale (1862)

Lavoisier, A.-L. Traité élémentaire de Chimie, Paris: Cuchet (1789). Translated as Elements of Chemistry. New York, Dover (1790)

Lavoisier, A.-L.: Oeuvres de Lavoisier, Correspondance volume VI, 1789-1791. In: Bret, P. (ed.). Paris, Académie des Sciences (1997) 
Lavoisier, A.-L., Brisson, M.J., Meusnier, J.B., Laplace, P.S.: Extrait des Registres de l'Académie Royale des Sciences, du 28 Août 1790. Ann. Chim. 7, 257-263 (1790)

Maclean, J.: Two Lectures on Combustion: Supplementary to a Course of Lectures on Chemistry. Read at Nassau-Hall. Containing an Examination of Dr. Priestley's Considerations on the Doctrine of Phlogiston and the Decomposition of Water. Dobson, Philadelphia (1797)

McEvoy, J.: Joseph Priestley and the chemical revolution: a thematic overview. In: Schwarz, A., McEvoy, J. (eds.) Motion Towards Perfection: The Achievement of Joseph Priestley, pp. 129-160. Skinner House, Boston (1990)

Mitchill, S.: An Attempt to accommodate the Dispute among the Chemists concerning Phlogiston. Letter to Dr Priestley dated Nov. 14, 1797. Med. Repos. 1, 514-521 (1798)

Murray, J.: A System of Chemistry, 4th edn. Francis Pillans, Edinburgh (1819)

Partington, J.: A History of Chemistry, vol. 3. Macmillan, London (1962)

Priestley, J.: Experiments and Observations on Different Kinds of Air. Johnson, London (1774)

Priestley, J.: Experiments and Observations on Different Kinds of Air, vol. II. Johnson, London (1775)

Priestley, J. Disquisitions Relating to Matter and Spirit. Johnson, London (1777). Page refs to Rutt, J. (ed.) The Theological and Miscellaneous Works of Joseph Priestley, vol III. London (1818a)

Priestley, J.: Experiments and Observations Relating to Various Branches of Natural Philosophy, with a Continuation of the Observations on Air, vol. I. Johnson, London (1779)

Priestley, J.: Experiments and Observations Relating to Various Branches of Natural Philosophy, with a Continuation of the Observations on Air, vol. II. Johnson, London (1781)

Priestley, J.: Experiments relating to phlogiston and the seeming conversion of water into air. Philos. Trans. R. Soc. Lond. 73, 398-434 (1783)

Priestley, J.: Experiments and observations relating to air and water. Philos. Trans. R. Soc. Lond. 75, 279309 (1785)

Priestley, J.: Reflections on the present state of free inquiry in this country, (1785b). Page refs to Rutt, J. (ed.) The Theological and Miscellaneous Works of Joseph Priestley, vol. XVIII. London (1818b)

Priestley, J.: Experiments and Observations Relating to Various Branches of Natural Philosophy, with a Continuation of the Observations on Air, vol. III. Johnson, London (1786)

Priestley, J.: A Letter to the Right Honourable William Pitt... on the Subjects of Toleration and Church Establishments: Occasioned by his Speech Against the Repeal of the Test and Corporation Acts, on Wednesday the 28th of March 1787. Johnson, London (1787)

Priestley, J.: Experiments and observations relating to the principle of acidity, the composition of water and phlogiston. Philos. Trans. R. Soc. Lond. 78, 147-157 (1788a)

Priestley, J.: Additional experiments and observations relating to the principle of acidity, the composition of water and phlogiston. Philos. Trans. R. Soc. Lond. 78, 313-330 (1788b)

Priestley, J.: Defences of Unitarianism for the Year 1786, 2nd edn. Johnson, London (1788c)

Priestley, J.: Defences of Unitarianism for the Year 1787. Johnson, London (1788d)

Priestley, J.: Objections to the experiments and observations relating to the principle of acidity, the composition of water and phlogiston. Philos. Trans. R. Soc. Lond. 79, 7-20 (1789)

Priestley, J.: Experiments and Observations on Different Kinds of Air, and Other Branches of Natural Philosophy, Connected to the Subject: Being the Former Six Volumes Abridged and Methodized, with Many Additions, vol. I, II, and III. Johnson, London (1790a, b, c)

Priestley, J.: Defences of Unitarianism for the Years 1788 and 1789. Johnson, London (1790)

Priestley, J.: Farther experiments relating to the decomposition of dephlogisticated and inflammable air. Philos. Trans. R. Soc. Lond. 81, 213-222 (1791)

Priestley, J.: Experiments on the Generation of Air from Water. Johnson, London (1793)

Priestley, J.: Heads of Lectures on a Course of Experimental Philosophy Particularly Including Chemistry, Delivered at the New College in Hackney. Johnson, London (1794)

Priestley, J.: Experiments and Observations Relating to the Analysis of Atmospherical Air; Also, Farther Experiments Relating to the Generation of Air from Water... to which are Added, Considerations on the Doctrine of Phlogiston and the Decomposition of Water. Johnson, London (1796)

Priestley, J.: Observations on the Doctrine of Phlogiston and the Decomposition of Water, Part II. Dobson, Philadelphia (1797)

Priestley, J.: A letter to Dr. Mitchill, in reply to the preceding. Jan. 18, 1798. Med. Repos. 1, 511-512 (1798)

Priestley, J.: The Doctrine of Phlogiston Established and that of the Composition of Water Refuted. Kennedy, Northumberland (1800)

Priestley, J.: Observations and experiments relating to the Pile of Volta: in a Letter from Dr. Priestley to Dr. Woodhouse, Sept. 16, 1801. Med. Repos. 5, 153-159 (1802)

Priestley, J.: The doctrine of phlogiston established and that of the composition of water refuted, 2 nd edn. Kennedy, Northumberland (1803) 
Priestley, J.: Memoirs of Dr Joseph Priestley. Johnson, London (1806)

Rodwell, G.: On the theory of phlogiston. Philos. Mag. J. Sci. 35, 1-32 (1868)

Rupp, T.L.: Remarks on Dr. Priestley's experiments and observations relating to the analysis of atmospherical air, and his considerations on the doctrine of phlogiston and the decomposition of water. Mem. Lit. Philos. Soc. Manch. 5, 123-162 (1798)

Sadouin-Goupil, M.: La correspondence Berthollet-Blagden. In: Histoire de la Chimie Depuis le XVIII Siècle. pp. 91-97. Paris, Librairie Albert Blanchard (1971)

Schofield, R.: Joseph Priestley, the theory of oxidation and the nature of matter. J. Hist. Ideas 25, 285-294 (1964)

Schofield, R.: A Scientific Autobiography of Joseph Priestley. MIT Press, Cambridge (1966)

Schofield, R.: The Enlightened Joseph Priestley. The Pennsylvania State University Press, University Park (2004)

Séguin, A.: Suite du Mémoire sur la Combustion du Gaz Hydrogène dans des Vaisseaux clos. Ann. Chim. 9, 30-50 (1791)

Thomson, T.: History of Chemistry. Colburn and Bentley, London (1830)

Van-Marum, M., de Lettre, M., van-Marum, M.: Berthollet. Ann. Chim. 12, 113-140 (1792)

Van Troostwijk, A., Deiman, J.: Sur une manière de decomposer l'Eau en air inflammable et en air vital. Obs. sur la Phys. 35, 369-378 (1789)

Verbruggen, F.: How to explain Priestley's defence of phlogiston. Janus 54, 47-89 (1972)

Withering, W.: Experiments and observations on the Terra Ponderosa, etc. Philos. Trans. R. Soc. Lond. 74, 293-311 (1784)

Woodhouse, J.: An answer to Dr Joseph Priestley's considerations on the doctrine of phlogiston, and the decomposition of water: founded upon demonstrative experiments. Trans. Am. Philos. Soc. 4, 452-475 (1799)

Woodhouse, J.: An account of the principal objections to the antiphlogistic system of chemistry. In: Parkinson, J. (ed.) The Chemical Pocket-Book, pp. 205-215. Humphreys, Philadelphia (1802) 